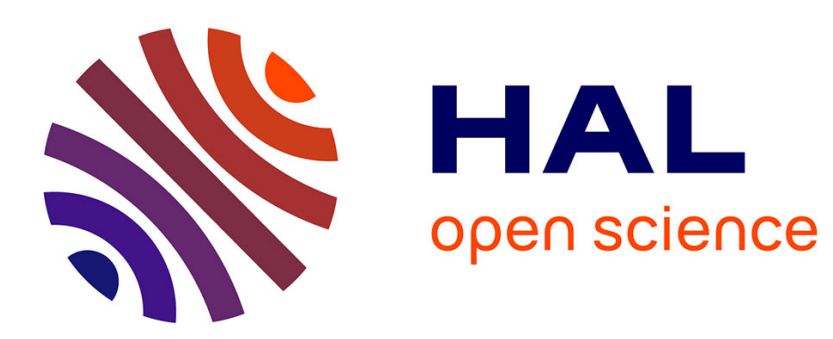

\title{
A review of volume changes in rubbers: the effect of stretching
}

Jean-Benoit Le Cam

\section{To cite this version:}

Jean-Benoit Le Cam. A review of volume changes in rubbers: the effect of stretching. Rubber Chemistry and Technology, 2010, 83, pp.247-269. 10.5254/1.3525684 . hal-01131582

\section{HAL Id: hal-01131582 \\ https://hal.science/hal-01131582}

Submitted on 13 Mar 2015

HAL is a multi-disciplinary open access archive for the deposit and dissemination of scientific research documents, whether they are published or not. The documents may come from teaching and research institutions in France or abroad, or from public or private research centers.
L'archive ouverte pluridisciplinaire HAL, est destinée au dépôt et à la diffusion de documents scientifiques de niveau recherche, publiés ou non, émanant des établissements d'enseignement et de recherche français ou étrangers, des laboratoires publics ou privés. 


\section{A REVIEW OF VOLUME CHANGES IN RUBBERS: THE EFFECT OF \\ STRETCHING}

JEAN-BENOÎT LE CAM

Clermont Université, Institut FrançAis de MécAnique Avancée, EA 3867, LABORATOIRE DE MÉCANIQUE ET INGÉNIERIES, BP 10448, F-63000 CLERMONT-FERRAND

\section{CONTENTS}

Page

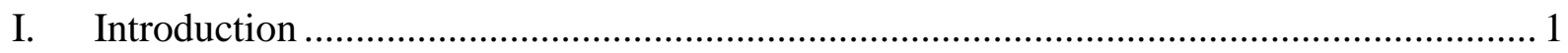

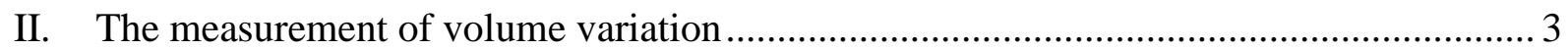

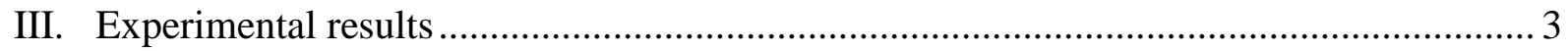

A. The works of schippel (1920) and feuchter (1925) ............................................... 4

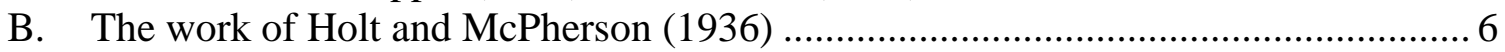

C. 1940-1980: most of the measurements are used for volume change modeling ......... 8

D. The most recent studies: toward the comprehension of deformation mechanisms .. 10

IV. Modeling volume change in stretched rubbers ........................................................ 14

A. Modeling the reversible change in volume under uniaxial loading conditions........ 15

B. Modeling the reversible change in volume under multiaxial loading conditions .... 23

C. Note on modeling the irreversible change in volume under multiaxial loading

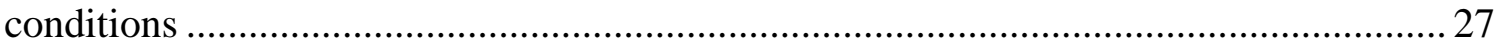

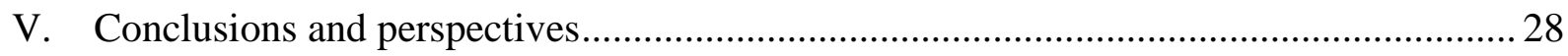

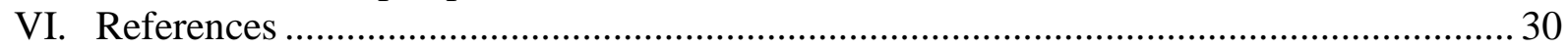

\section{INTRODUCTION}

Before the 20th century, only a few brief observations on rubber properties were reported; for instance those of Gough ${ }^{1}$ (1805) and Joule ${ }^{2}$ (1857), which dealt with the increase in temperature of rubber when stretched and are classically cited in the literature. The first studies that investigated the mechanical properties of rubber date from the beginning of the 20th century. A major result was the observation of the decrease in stiffness of rubber during 
the first mechanical cycles by Bouasse and Carrière ${ }^{3}$ (1903). Later, this phenomenon was studied more precisely by Holt ${ }^{4}$ (1931) and Mullins ${ }^{5}$ (1948) and was then referred to as "the Mullins effect". Other physical phenomena involved in the deformation of rubber were also characterized by using advances in physics and technology. For example, x-ray diffraction contributed to the comprehension of the kinetics of polymer chain crystallization. Today, rubber is still the object of vivid scientific interest and a material with "extraordinary physical properties". 6

To investigate these physical properties, several mechanical quantities have been used. Among them, the change in volume of stretched rubber seems to be one of the most relevant, in particular to analyze the change in the rubber microstructure. The first record of this phenomenon dates back as far as the end of the nineteenth century in the works of Joule ${ }^{6}$ (1884). The author observed that the specific gravity of natural rubber decreased upon stretching it (about 0.15 per cent for a 100 per cent stretch). Even though these results were corroborated by Mallock $^{7}$ (1889) while investigating the physical properties of vulcanized India-Rubber, Thomson ${ }^{8}$ stated (1890) that a column of rubber when stretched out suffers no significant change in volume and rubber may therefore be regarded as an incompressible elastic solid. Then, while studying the nature of the stress-strain curves for rubber containing different pigments in varying quantities, Schippel $^{9}$ (1920) considered that possibly, when the rubber was sufficiently stretched, it might pull away from the particles of pigment along their axes of stress and cause vacua to be formed on either side of each particle, and a considerable increase in the rubber body volume might therefore be observed. Later, the discovery of the ability of rubber chains to crystallize under stretching or at low temperature motivated a number of authors to investigated more precisely the change in volume of rubbers, under stretching and/or under heating and cooling. 
The aim of the present paper is to give an exhaustive view of the state of knowledge on volume variation and to link it to the physical phenomena observed. For this purpose, the results obtained experimentally are first presented in a chronological manner. Special attention is paid to detailing their relative contribution. Secondly, the different approaches adopted to modeling the isothermal volume changes in stretched rubbers are summarized. Finally, conclusions and perspectives close the paper.

\section{THE MEASUREMENT OF VOLUME VARIATION}

Numerous measurement methods have been used to characterize the change in volume of stretched rubbers. They used various technologies whose accuracy differed from one to another. Moreover, loading and temperature conditions are not precisely described. This explains why the results obtained are not easily comparable. The technology classically used to measure volume variation is dilatometry. In this case, the measurement of the change in volume of rubber is performed by enclosing samples in suitable confining liquids in dilatometers and observing the changes in the height of the liquid in calibrated capillary tubes when the rubber is stretched. Smaller capilaries give more precise values. ${ }^{4,10,11}$ Certain authors developed their own procedure to measure the volume change, which can be determined by calculating the change in specific gravity ${ }^{9}$, measuring the hydrostatic weighting ${ }^{12-14}$ or measuring the relative pressure using the Farris principle ${ }^{15}$. Optical measurement methods have also been developed recently by Le Cam and Toussaint. ${ }^{16,17}$

\section{III.EXPERIMENTAL RESULTS}


As previously indicated in the introductory section, even though preliminary observations of the change in volume of stretched rubber were briefly reported by investigators at the end of the $19^{\text {th }}$ century ${ }^{6-8}$, the first quantitative studies date from the beginning of the 20th century. In this section, we propose to review the main results obtained from this period in a chronological manner.

\section{A. THE WORKS OF SCHIPPEL (1920) AND FEUCHTER (1925)}

The work of Schippel ${ }^{9}$ was the first to investigate quantitatively the change in volume of stretched natural rubber. Schippel investigated the volume change in stretched rubber containing various pigments. This study was motivated by previous experiments by the author on transparent vulcanized compounds containing a fair proportion of medium-sized lead shot. When the compound was stretched, the formation of vacua proceeded gradually until each lead shot had its own conical vacuum on either side in the direction of strain. To investigate more precisely this phenomenon, this author added pigments (here given in phr (part per cent of rubber) by volume) in varying quantities to the rubber matrix: barytes, i.e. barium sulfate (BaSO4), from 0 to 150 , whiting from 0 to 150 , zinc oxide from 0 to 125 , china clay from 0 to 25, red oxide from 0 to 30 , lamp carbon from 0 to 75 and carbon black from 0 to 30 . The tests were carried out until sample fracture. For each particle type, the increase in volume was measured every 50 per cent strain increase up to a 200 or 300 per cent strain. The final curve describing relative volume variation versus elongation was obtained by linking the last point at 200 or 300 per cent strain to the point corresponding to the sample fracture. This is illustrated by the diagram in Figure 1. Results obtained by Schippel showed that the higher the quantity of particles, the higher the volume increase and the lower the elongation before fracture. The maximum of change in volume was found to attain $120 \%$ for the barite particles. 
Regarding the effect of zinc oxide, Schippel highlighted that a threshold of $40 \mathrm{phr}$ in volume was necessary to obtain a higher increase in volume for a given elongation, and concluded that below this threshold, zinc oxide had no effect on volume change. The author also found that the mean diameter of the particles had the same effect as the quantity. Finally, Schippel chose the level of change in volume as a relevant measure of adhesion and classified red oxide, zinc oxide, lamp black and carbon black as particles that exhibited a strong adhesion with the rubber matrix, contrary to barites and whiting. In Figure 1, this latter observation can be illustrated by angle $\alpha$, which is large for barites and whiting, and small for the other particles. The fact that the volume can not exceed a certain value, modeled by a value of angle $\alpha$ close to $\pi / 2 \mathrm{rad}$, seems to be a criterion of high adhesion between particles and the rubber matrix for Schippel.

Later, a brief study by Feuchter ${ }^{18}$ reported some results that differed from those of Schippel by showing that the volume of natural rubber decreased with elongation. The author explained this result by the formation of an anisotropic system in stretched natural rubber, namely fibering or crystallization. This result, which seems to be contradictory to that of Schippel, is the first that envisaged that volume might decrease through the contribution of phenomena that tend to reorganize the polymer chains. Moreover, compared to the previous work of Schippel, the fact that no increase

in volume of rubber was observed can be explained by the fact that Feuchter studied an unfilled natural rubber. Thus, the decrease in volume of rubber due to crystallization is a firstorder phenomenon compared to the cavitation phenomenon. In Schippel's study, the presence of fillers was favorable and amplified the cavitation. Finally, the decrease in the volume of rubber was observed by Feuchter beyond a certain elongation threshold in the range of elongation for which Schippel had not measured the volume. Even though a second-order phenomenon had taken place, Schippel did therefore not detect it. 
At this stage of the present literature survey, the volume variation in rubber seems to be affected by two major phenomena: nucleation and the growth of vacua around the particles, which leads to an increase in volume, and the reorganization of polymer chains beyond a certain elongation threshold, namely crystallization, which leads to the opposite effect. With regard to these phenomena, some questions of importance arise: Are they reversible? Are they simultaneous? Is the elongation at which crystallization occurs constant or is it dependent on time, polymer chains, polymer network and/or temperature? The first observations previously summarized illustrate the complexity of the phenomena that occur during the deformation of rubber. This is the reason why a number of experimental techniques were used to investigate this deformation. For instance, by means of x-rays, a time lag was observed in the double refraction of stretched rubber. ${ }^{19-21}$ This time lag is also necessary to obtain the stabilization of the volume at a given elongation ${ }^{22}$. Again, this could explain the phenomenon called "optical creep" and observed by photoelasticity by Thibodeau and McPherson. ${ }^{23}$ These results motivated the study on the change in volume of stretched rubber by Holt and McPherson ${ }^{11}$.

\section{B. THE WORK OF HOLT AND MCPHERSON (1936)}

In this work ${ }^{11}$, the authors conducted two series of experiments with unfilled samples vulcanized with sulfur. In the first series, the rubber was stretched at $25^{\circ} \mathrm{C}$ to a given elongation and held at that elongation for 3 minutes, observations on the volume being made at frequent intervals. It was then released and observations were again taken at intervals over a period of 3 minutes. The same procedure was repeated for various successive elongations. The results are illustrated by the diagram in Figure 2. A decrease in volume corresponding to $0.1 \%$ in 3 minutes was observed beyond an elongation equal to $450 \%$. At higher elongations 
the decrease became progressively greater and amounted to nearly $2 \%$ at an elongation of $725 \%$.

In a second series of experiments the samples were stretched at $25^{\circ} \mathrm{C}$ first to a relatively low elongation of 200 percent, and were held at this elongation for 3 minutes while observations were made. Then, without release, the sample was stretched to successively higher elongations, each for 3 minutes, until the maximum elongation had been reached. The process was then reversed by the same stepwise procedure. The results are illustrated in Figure 3. The changes in volume at different elongations were slightly greater than the changes which were observed when the samples were released between successive elongations. Moreover, when the sample was released in a stepwise manner the volume showed a definite lag, and at any elongation except zero it was less than the volume attained on stretching to the same elongation. At zero elongation, the original volume was recovered. The authors interpreted these results as the fact that the release phase might correspond to the equilibrium state, but they reported that this was not in agreement with the fact that when rubber is held for a longer time in the stretched condition, its volume may reach lower values. The authors also explained that there is an elongation threshold of about $450 \%$ beyond which volume variation became apparent. Thus, the results of Holt et al. were the first from which the elongation at the beginning of crystallization can be deduced. Indeed, during stretching, the decrease in volume became apparent when the elongation at the beginning of crystallization was reached. Moreover, the time necessary to stabilize the volume at a given elongation was higher during stretching than during the release phase. The authors concluded that the change in volume during stretching is influenced by the same considerations as X-ray diffraction, since it is observed only above a certain critical elongation and is greater the higher the elongation, the lower the temperature, and the longer the time the sample is maintained stretched. 
Finally, this study by Holt and McPherson gave the first observations on the influence of repeated cycles on the change in volume: after a first set of elongations was applied and the samples were maintained stretched, the same set of elongations was applied again to the samples. The authors concluded that the change in volume on stretching was not significantly affected by the previous stress history of the samples and this is therefore in contrast to stressstrain behavior, which is markedly altered by the first few stretching cycles. ${ }^{3-5}$

\section{1940-1980: MOST OF THE MEASUREMENTS ARE USED FOR VOLUME CHANGE MODELING}

During this period, a number of authors tended to predict the volume change in rubber from measurements at low elongations. ${ }^{12,24-29}$ Some of these authors cast doubts on the measurements performed by Holt and MacPherson for low elongation values (up to 200\% elongation). For instance, Gee ${ }^{12}$ considered that the dilatometric method used by Holt and McPherson was not sufficiently sensitive to measure volume change in this elongation range, and performed the measurement with a new apparatus using hydrostatic weighting; they found, contrary to Holt and McPherson, a significant volume variation of about $210^{-4}$ at $125 \%$ elongation. In the larger elongation ranges, the studies that attempted to model the volume change at elongations superior to $200 \%$ were conducted with filled synthetic rubbers such as styrene butadiene rubber ${ }^{30}$ and Viton ${ }^{31}$, i.e. non-crystallizable rubbers for which the volume increases in a monotonic manner when stretched. The models proposed in the literature are summarized in the next section.

It should be noted that, in this period, the work of Mullins and Tobin ${ }^{13}$ is the only one that investigated volume variation in stretched rubber, unfilled or filled by carbon black, vulcanized using sulphur or peroxides, in the large elongation ranges. This work reconciled the previous results on volume variation at low elongations with those obtained by Holt and 
McPherson at large elongations: Mullins and Tobin showed that the volume always increased before decreasing. The decrease is the consequence of crystallization, which takes place above a certain elongation value. For filled rubber vulcanized with sulphur, the decrease began between 100 and $200 \%$ elongation. For unfilled rubber vulcanized with sulphur, the maximum applied elongation of $400 \%$ was not sufficient to highlight a decrease in rubber volume. This seems to indicate that fillers act, at the microscopic scale, as concentrators of the deformation and allow crystallization to occur at lower macroscopic elongation. For unfilled rubber vulcanized using peroxides, the decrease began between 200 and 300\% elongation (this result was also found by Reichert, Hopfenmüller and Göritz. ${ }^{32}$ Compared to vulcanization with sulphur, this observation seems to indicate that vulcanization with peroxides leads to a higher deformation localization than vulcanization with sulphur and thus acts like fillers do. Finally, Shinomura and Takahashi ${ }^{33}$ measured the volume changes in carbon black-filled butyl and styrene butadiene rubbers and proposed to distinguish two parts in the response of the materials in terms of relative volume variation. As shown in Figure 4, volume variation versus elongation can be modeled by two curves, each of them corresponding to one type of cavitation. The authors explained that the first type of cavitation originates in the breakdown of carbon black-rubber interactions and the second type comes from the breakdown of carbon black aggregates. Thus, they proposed to analyze volume variation by introducing a new mechanical quantity defined as the ratio between the volume variation and the uniaxial Cauchy stress $\sigma$. Figure 5 shows the results obtained. As previously, in Figure 4, this relation is modeled by two curves, corresponding to the first and second type of cavitation. The first curve exhibited a plateau whose level depends on the filler structure and the interaction between fillers and the rubber matrix. 
Finally, elongation threshold is observed before volume variation. It should be noted that in this work the uniaxial Cauchy stress is calculated using the assumption that the material is incompressible.

\section{THE MOST RECENT STUDIES: TOWARD THE COMPREHENSION OF DEFORMATION MECHANISMS}

In the recent past, fives studies have been dedicated to volume variation in stretched rubbers. They were carried out on synthetic and natural rubbers and tended to link the measurements to the mechanisms of volume change and consequently of deformation. The first two investigated the nature and the surface treatment of fillers in synthetic rubber. The study by Kumar et al. $^{14}$ (2007) dealt with the incorporation of recycled rubber granulates, considered as intrinsic flaws, in a virgin styrene butadiene rubber matrix. No volume change with strain was observed in this matrix, unfilled or filled with 70 phr carbon black aggregates (N330, HAF). Authors measured the volume variation in stretched compounds with various granulate size and modulus and investigated the change in flaw size with strain and the reduction in strength resulting from a weaker interface using a microstructural finite element analysis. Results highlighted that flaw size increases in a characteristic way with strain if the rubber matrix and granulates have a similar modulus, whereas a modulus mismatch results in much larger volume changes and hence greater flaw size which also appears to increase with strain. As a perspective, authors suggested that their approach would be well-suitable to evaluate the effectiveness of surface modification techniques in the future. $^{34-36}$

This was the aim of the study of Ramier et $a l .{ }^{37}$ (2007) that focused on the influence of the treatment of silica fillers in styrene butadiene rubber. These fillers were treated with either a covering agent or a coupling agent. First, tests performed previously on the rubber matrix 
had not highlighted any change in volume. Second, without any treatment, silica-filled styrene butadiene rubber exhibited the highest volume variation at each applied elongation. Third, for both silica filler treatments, volume variation increased monotonically with elongation. Using the covering agent, the higher its quantity, the lower the volume variation. Using the coupling agent, the curve is the same whatever its quantity. Moreover, as illustrated in Figure 6, the concavity of the curves obtained for the two treatments was different. By plotting volume variation as a function of stress, the authors concluded that the covering agent is favorable to decohesion and void formation phenomena and that the coupling agent delays the occurrence of decohesion because of the strong cohesion between treated silica fillers and the rubber matrix.

After these first results on styrene butadiene rubber, some of the previous authors attempted to determine parameters governing strain-induced crystallization in filled natural rubber. ${ }^{15}$ For this purpose, the authors measured simultaneously the tensile stress, the volume variation and the crystallinity of filled and unfilled natural rubbers (Standard Malaysian Rubber number 10). Three kinds of carbon black (N324, N347 and N330) and one type of silica were used to fill the samples ( $45 \mathrm{phr}$ in weight for carbon black and 50 for silica). Tests were performed over several cycles at a temperature and a strain rate set at $20^{\circ} \mathrm{C}$ and 0.25 $\min ^{-1}$, respectively. Figure 7 illustrates the results obtained with all the samples. During stretching, filled natural rubbers exhibited a positive volume variation due to filler-rubber decohesion and cavitation in the rubber matrix. The maximum value of the positive volume variation (less than $4 \%$ for carbon black filler referred to as N234) decreased with each cycle until stabilization. Even through the authors located the stabilization of the tensile stress after the third cycle, they did not discuss the number of cycles necessary to stabilize the volume variation. During unloading, they observed that for a given elongation the volume variation is lower and they explained this result by a fast recovery of decohesion /cavitation. They also 
observed that volume variation became negative before returning to zero. For the authors, this is the signature of strain-induced crystallization, which tends to reduce significantly the volume of rubber. To highlight the influence of fillers, they measured the volume change for the same natural rubber, unfilled. It should be noted that they did not indicate whether the curve was that of the stabilized cycle or not. For unfilled natural rubber, the maximum value for volume variation reached $2 \%$ and no negative value was observed. This could be explained by the fact that the elongation at the beginning of crystallization had not been attained during stretching. They proposed to illustrate the contribution of both cavitation/decohesion and crystallization phenomena to the global change in volume measured by the diagram in Figure 8. The authors explained that they were not able to analyze more precisely their results in terms of change in volume between the different filled samples because the accuracy of the pressure sensor they chose for the apparatus used to measure the volume was not high enough.

At this stage in the present state-of-the-art review, it seems relevant to be able to distinguish the contribution of decohesion/cavitation and crystallization phenomena and to study quantitatively the competition between the two phenomena through the measurement of the change in volume. For this purpose, it is necessary to measure the volume variation more accurately. This was the aim of the two last studies who introduced an original volume measurement method. ${ }^{16-17}$ This is based on an optical measurement technique, namely digital image correlation (D.I.C). In their work, Le Cam and Toussaint investigated the competition between cavitation/decohesion and crystallization by detecting elongations at the beginning of crystallization and at the melting of crystallites. ${ }^{16}$ Tests were performed on both natural and synthetic rubbers, unfilled and filled with carbon black, and at a temperature, hygrometry and strain rate set at $23^{\circ} \mathrm{C}, 34 \%$ and $1.3 \mathrm{~min}^{-1}$, respectively. The results obtained are presented in Figures 9 to 13. Figure 9 shows the relative volume variation obtained during the first 
mechanical cycle for unfilled natural rubber. The authors modeled the curve in four segments ([OA], $[\mathrm{AB}],[\mathrm{BC}]$ and $[\mathrm{CD}])$ and described the competition between cavitation and stressinduced crystallization in relation to each segment:

(i) segment [OA]: the volume increases due to the occurrence and growth of cavities in the rubber matrix;

(ii) segment $[\mathrm{AB}]$ : from $\lambda_{A}=4.2$, the volume begins to decrease. According to the authors, even though cavities continue to appear and grow, the crystallization of the polymer chains begins and is of a first-order phenomenon compared to cavitation. Consequently, in the unfilled natural rubber considered in this study, the volume decreases;

(iii) segment $[\mathrm{BC}]$ : during unloading, the sample volume at a given stretch ratio is smaller than during loading. According to the authors, this could be due to either the difference between the kinetics of crystallization and of crystallite melting or the anelastic deformation of cavities. To investigate the deformation of cavities, the authors measured the volume over one cycle for which the maximum stretch ratio is still inferior to $\lambda_{A}$, i.e. the stretch ratio at which crystallization is initiated. In terms of stress, the authors explained that the hysteresis loop was not significant because no crystallization occurs in the bulk material. This result corresponds to that of Trabelsi, Albouy and Rault ${ }^{38}$. Figure 10 shows that the volume change is the same for loading and unloading. The authors concluded that cavitation generated under such loading conditions can be considered as an elastic process and that the kinetics of the nucleation and growth of cavities and recovery can be considered as being the same on the macroscopic scale. These results would indicate that the hysteresis loop obtained for volume change curves is only due to chain crystallization. Finally, point $\mathrm{C}$ corresponds to the melting of the last crystallites;

(iv) segment $[\mathrm{CD}]$ : the volume slightly decreases when the cavities close. 
The authors then conducted the same measurements with the same natural rubber filled with $34 \mathrm{phr}$ of carbon black referred to as N326. Figure 11 presents the result obtained in terms of relative volume variation for the first mechanical cycle. As shown in this figure, the addition of fillers increased the volume variation. The fact that from $\lambda_{A}=1.64$ the volume variation does not decrease as in natural rubber indicates that, even though the elongation at crystallization is lower than in natural rubber, the addition of fillers tends to amplify the cavitation phenomenon and to minimize the level of crystallinity for a given stretch ratio. For the authors, this is the reason why the hysteresis loop was smaller in filled than in unfilled natural rubber. Moreover, the addition of fillers amplifies the local deformation and consequently decreases the elongation at which crystallization begins.

To conclude their work on volume change in rubbers, Le Cam and Toussaint performed cyclic tensile tests on natural and synthetic filled rubbers. ${ }^{17}$ Figures 12 and 13 show the third cycle in terms of relative volume variation obtained for filled natural rubber and styrene butadiene rubber, respectively. For filled natural rubber, the hysteresis loop of the relative volume variation curve obtained for the third mechanical cycle was lower than for the first cycle. Moreover, the same characteristic stretch ratios as those of the first cycle were observed: crystallization started at $\lambda=1.64$ and the last crystallites melted at $\lambda=1.44$. For the authors, this seems to indicate that the Mullins effect has no influence on these characteristic elongations. For filled styrene butadiene rubber, the first cycle was the only one that exhibited a hysteresis loop in the volume change curve. No hysteresis loop was observed for the second and third cycles and the evolution of volume variation versus stretch ratio was linear. Moreover, no significant residual volume variation was observed.

These studies close the first part of the present review.

\section{MODELING VOLUME CHANGE IN STRETCHED RUBBERS}


As highlighted above, the response of stretched rubbers in terms of volume change comes from several physical phenomena. Obviously, the prediction of the relative volume change of stretched rubber does not account for all of these phenomena and their modeling is still a question of importance. This section presents the approaches proposed to model the volume change. The first models date from the 1950s and predict the reversible change in volume of isotropic rubber submitted to monotonic uniaxial stretching. Later, the prediction of change in volume was performed for multiaxial loading conditions. After reporting the uniaxial and multiaxial predictions of the change in volume of stretched rubber, a note is dedicated to volume changes due to the irreversible process of deformation. It should be noted that the influence of temperature on volume change is not discussed here.

\section{A. MODELING THE REVERSIBLE CHANGE IN VOLUME UNDER UNIAXIAL LOADING CONDITIONS}

The first study that tried to model the change in volume of stretched rubber was that of $\mathrm{Gee}^{25}$ (1946). The author assumed that the magnitude of the volume change can be estimated, at least approximately, from the known dependence of the internal energy $E$ of rubber on isotropic changes in volume and used the well-known expression ${ }^{39}$ :

$$
\left(\frac{\partial E}{\partial V}\right)_{T}=3 \frac{\beta T}{K}
$$

where $K=-\left(\frac{\partial \ln \mathrm{V}}{\partial P}\right)_{T}$ is the isothermal compressibility and $\beta$ is the coefficient of linear expansion of the unstretched rubber. It should be noted that this equation does not take into account the change in entropy due to phenomena such as crystallization of polymer chains and the fact that $\beta$ depends on the value of the elongation ${ }^{40}$. Assuming that the isothermal 
change of $E$ with $V$ is the same whether a hydrostatic pressure or a uniaxial tension is applied, the volume variation obtained by stretching the rubber to length $l$ is given by:

$$
\Delta V=\frac{K}{3 \beta T} \int_{l_{0}}^{l} l\left(\frac{\partial E}{\partial l}\right)_{P, T} d l
$$

where $l_{0}$ is the unstrained length of the rubber at temperature $T$. This equation applies as long as the material remains isotropic. According to $\mathrm{Gee}^{25}$, this assumption is valid for elongations inferior to 2 in natural rubber but he did not discuss the frontier between isotropy and anisotropy in terms of elongation. Moreover, Gee, examining the results of Holt and McPherson $^{11}$ in this range of elongation, assumed that the volume does not increase significantly with the increase in temperature at constant pressure and deformation. Considering his experimental data, the author rewrote Equation 2 as follows:

$$
\Delta V=\frac{1}{3} K \int_{l_{0}}^{l} l\left(\frac{\partial f}{\partial l}\right)_{P, T} d l
$$

where $f$ is the uniaxial tensile force. Finally, Gee discussed the origin of volume and energy changes and explained that for the classical theory of small elastic deformations, the applied force may be resolved into shear stresses, which change the shape of the material without affecting its volume, and a hydrostatic component, which changes the volume but not the shape. The hydrostatic component induced by a unidirectional force is a tension $-p$, equal in magnitude to one-third of the tensile stress:

$$
p \approx-\frac{1}{3} \frac{f l}{V}
$$

and the resulting volume variation $\Delta \mathrm{V}$ would equate $-p K V$ and consequently $\frac{1}{3} K f l$. The fact that this result can be obtained with the limiting form of Equation 3 as $l \rightarrow l_{0}$ shows that, for small deformations, the observed volume variation is produced by the hydrostatic component of the tensile force. According to Gee, this consists of an increase in the average 
intermolecular spacing, and is accompanied by equivalent increases in both internal energy and entropy.

Later, Hewitt and Anthony ${ }^{26}$ (1959) rewrote Equation 3 in the form:

$$
\frac{\Delta V}{V_{0}}=\frac{1}{3 B} \int_{1}^{\lambda} \lambda\left(\frac{\partial \Pi}{\partial \lambda}\right)_{P, T} d \lambda
$$

where $B$ is the bulk modulus of the rubber, $\Pi$ is the uniaxial component of the first PiolaKirchhoff tensor, $P$ is the pressure of the surrounding fluid (about $1 \mathrm{~atm}$ ) and $\lambda$ is the ratio between the deformed and undeformed lengths of the sample. This equation obviously applies in the same elongation range as Equation 2, i.e. inferior to 2.

To predict the relative volume variation using Equation 5, it is necessary to estimate $\Pi$. Here, we briefly recall the two theories classically applied. The first is the elementary statistical theory for idealized networks and is based on the postulate that the elastic free energy of a network is equal to the sum of the elastic free energies of the individual chains. ${ }^{41-}$ ${ }^{42}$ This leads us to neglect the intermolecular contributions to the total elastic free energy. ${ }^{43-44}$ The expression of the elastic free energy is given by:

$$
\Delta A_{e l}=\Im k T\left(\lambda_{1}^{2}+\lambda_{2}^{2}+\lambda_{3}^{2}-3\right)
$$

where the $\lambda_{\mathrm{i}}$ terms are the macroscopic principal extension ratios, i.e. the ratio between the deformed and undeformed macroscopic dimensions of a prismatic test sample if the macroscopic state of deformation may be assumed to be homogeneous. $k$ is the Boltzmann constant, $T$ is the absolute temperature and $\mathfrak{I}$ depends on the model considered. It is equal to $\frac{v}{2}$ for the affine network model, ${ }^{45}$ where $v$ is the number of network chains. It is equal to $\frac{\xi}{2}$ for the phantom network model, ${ }^{46}$ where $\xi=\left(1-\frac{2}{\phi}\right) \nu$ and $\phi$ is the average functionality, i.e. the number of sites from which chains can grow. According to Flory, the $A_{e l}$ expression contains an additional logarithmic term that is a gas-like contribution resulting from the 
distribution of the cross-links over the sample volume. Therefore, the affine model proposed by Flory $^{45}(1953)$ is rewritten as follows:

$$
\Delta A_{e l}=\frac{\nu k T}{2}\left(\lambda_{1}^{2}+\lambda_{2}^{2}+\lambda_{3}^{2}-3\right)-\mu k T \ln \left(\frac{V}{V_{0}}\right)
$$

where $\mu$ equals $2 \frac{v}{\phi}, V$ is the final volume of the network, and $V_{0}$ is the volume of network in the state of formation.

The stress derives from the elastic free energy, according to the thermodynamic expression: ${ }^{47}$

$$
\sigma_{i}=V^{-1} \lambda_{i}\left(\frac{\partial \Delta A_{e l}}{\partial \lambda_{i}}\right)_{T, V}
$$

where $\sigma_{i}$ is the Cauchy stress along the $i$ th coordinate direction, i.e. $\vec{x}, \vec{y}$ and $\vec{z}$ axes. The subscripts $T$ and $V$ indicate that the differentiation is performed at fixed temperature and volume.

The volume ratio is defined by:

$$
\frac{V}{V_{0}}=\lambda_{1} \lambda_{2} \lambda_{3}
$$

By considering that the volume of the network $V$ without any applied force at the beginning of the experiment may be different from $V_{0}$, depending on the amount of solvent present relative to that during formation, the final elongation is defined by:

$$
\lambda_{i}=\left(\frac{V}{V_{0}}\right)^{\frac{1}{3}} \alpha_{i}
$$

where $\alpha_{i}$ is the ratio between the final length of the network $l_{i}$ and its initial undistorted length at volume $V$ with solvent $l_{S i}$ along the $i$ th coordinate direction. In order words, this is similar to the multiplicative decomposition of the deformation tensor gradient when considering the 
continuum mechanics approach. The deformation comes from a purely dilatational part (which is the swollen step here, before any stretching), and an isochoric part.

Equation 9 leads us to rewrite Equation 8 as:

$$
\sigma_{i}=V^{-1} \lambda_{i} \sum_{S=1}^{3}\left(\frac{\partial \Delta A_{e l}}{\partial \lambda_{S}^{2}}\right) \frac{\partial \lambda_{S}^{2}}{\partial \lambda_{i}}
$$

and using Equation 6:

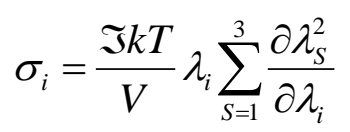

In the following, we present the prediction of uniaxial volume change. It is therefore necessary to develop the uniaxial stress-strain response. The deformation state along the $\vec{x}$ axis for stretching and compression is given by:

$$
\begin{gathered}
\lambda_{1}=\alpha\left(\frac{V}{V_{0}}\right)^{\frac{1}{3}} \\
\lambda_{2}=\lambda_{3}=\alpha^{-\frac{1}{2}}\left(\frac{V}{V_{0}}\right)^{\frac{1}{3}}
\end{gathered}
$$

where $\alpha$ corresponds to $\alpha_{1}$, i.e. the ratio of the final length along the direction of stretch to the initial undistorted length at volume $V$. Thus, Equation 12 has the form:

$$
\sigma_{1}=\frac{\mathfrak{J} k T}{V} \lambda_{1} \sum_{S=1}^{3} \frac{\partial \lambda_{S}^{2}}{\partial \alpha} \frac{\partial \alpha}{\partial \lambda_{1}}
$$

and using Equation 14 leads to:

$$
\sigma_{1}=2\left(\frac{\mathfrak{J} k T}{V}\right)\left(\frac{V}{V_{0}}\right)^{\frac{2}{3}}\left(\alpha^{2}-\alpha^{-1}\right)
$$


Finally, the retraction force $f$ acting along the $\vec{x}$ axis is obtained by multiplying both sides of the previous equation by the deformed area:

$$
f=2\left(\frac{\Im}{L_{i 1}}\right)\left(\frac{V}{V_{0}}\right)^{\frac{2}{3}}\left(\alpha-\alpha^{-2}\right)
$$

where $L_{i 1}$ is the dimension of the network in the $\vec{x}$ axis at the beginning of the experiment, when the volume differs from $V_{0}$ and depends on the quantity of solvent (see Figure 6.1, page 42 in reference 42). It should be noted that the retraction force can also be normalized by the unstrained area. Thus, the stress-strain response of the material is given for low elongation and at constant temperature by the statistical theory:

$$
\Pi=U T\left[\lambda-\frac{1}{\lambda^{2}}\right]
$$

where $U$ is related to the chain molecular weight $M_{c}$, the density $\rho$ of the rubber, and the gas constant $R$ by the relation $U=\frac{\gamma \rho R}{M_{c}} \cdot \gamma$ depends on the particular version of the statistical theory employed and on the structure of rubber. ${ }^{46}$ Its value is in the range $\frac{1}{2}$ to 2 .

Another one-parameter expression for $\Pi$ was proposed by considering that $\Pi$ remains strictly proportional to strain for strains up to $100^{48}$ or $200 \% .^{49}$ Hence, the stress-strain response is given by:

$$
\Pi \lambda=E \varepsilon
$$

where $E$ is the Young's modulus of the material and $\varepsilon$ the uniaxial linearized deformation, defined by $\frac{l-l_{0}}{l_{0}}$.

An additional one-parameter stress-strain relationship was proposed by Valanis and Landel ${ }^{50}(1967)$ in the logarithmic form: 


$$
\Pi=\frac{2}{3} E \ln \lambda\left(1+\frac{1}{2 \lambda^{\frac{3}{2}}}\right)
$$

Finally for this first theory, a two-parameter relationship was proposed by Martin, Roth and Stiehler $^{51}$ (1956) which has the form:

$$
\Pi=E\left(\frac{1}{\lambda}-\frac{1}{\lambda^{2}}\right) \exp \left[A\left(\lambda-\frac{1}{\lambda}\right)\right]
$$

where $A$ is a parameter which depends on both the degree of crosslinking and the timescale.

The second theory used to model the stress-strain response of rubber-like material is based on hyperelasticity, by considering the medium as a continuum. A number of models of various complexity have been proposed; see for example: Mooney ${ }^{52}$ (1940); Treloar $^{53}$ (1943); Rivlin $^{54,55}$ (1948); Biderman $^{56}$ (1958); Hart-Smith ${ }^{57}$ (1966); Yeoh $^{58,59}$ (1993, 1997); Gent $^{60}$ (1996); Haines and Wilson ${ }^{61}$ (1979); Gent and Thomas ${ }^{62}$ (1958); and Ogden ${ }^{63}$ (1972). In the case of Mooney hyperelasticity:

$$
\Pi=2\left(\lambda-\frac{1}{\lambda^{2}}\right)\left(C_{1}+\frac{C_{2}}{\lambda}\right)
$$

where $C_{1}$ and $C_{2}$ are the material parameters of Mooney's law.

Using the expression of relative volume variation given by Equation 3, Fedors and Landel $^{30}$ (1970) proposed to compared the results obtained with the previous stress-strain expressions. Thus, the calculation of the integral of Equation 3, using Equation 18, leads to the expression of relative volume change:

$$
\frac{\Delta V}{V_{0}}=\frac{U T}{3 B}\left[\frac{\lambda^{2}-1}{2}+\frac{2(\lambda-1)}{\lambda}\right]
$$

This equation can be rewritten as follow ${ }^{26}$ : 


$$
\frac{\Delta V}{V_{0}}=\frac{E}{9 B}\left[\frac{\lambda^{2}-1}{2}+\frac{2(\lambda-1)}{\lambda}\right]
$$

Using Equation 19, Equation 3 becomes:

$$
\frac{\Delta V}{V_{0}}=\frac{E}{3 B} \ln \lambda
$$

Using Equation 20, Equation 3 becomes:

$$
\frac{\Delta V}{V_{0}}=\frac{2 E}{9 B}\left[\lambda+\frac{2}{\lambda^{\frac{1}{2}}}+3 \frac{\ln \lambda}{2 \lambda^{\frac{1}{2}}}-3\right]
$$

These expressions of relative volume variation result from a one-parameter stress-strain relationship. For instance, using Equation 22, the two-parameter expression of relative volume variation would be:

$$
\frac{\Delta V}{V_{0}}=\frac{2 C_{1}}{3 B}\left[\frac{1}{2} \lambda^{2}-\frac{2}{\lambda}-\frac{3 C_{2}}{2 C_{1} \lambda}+\frac{3}{2}\left(1+\frac{C_{2}}{C_{1}}\right)\right]
$$

and using the expression of Martin, Roth and Stiehler ${ }^{51}$ (1956):

$$
\frac{\Delta V}{V_{0}}=\frac{E}{3 B} \int_{1}^{\lambda} \frac{A \lambda^{3}-(A+1) \lambda^{2}+(A+2) \lambda-A}{\lambda^{-4}} \exp \left[A\left(\lambda-\frac{1}{\lambda}\right)\right] d \lambda
$$

Once the value of $A$ has been determined, the integral can be evaluated numerically. It should be noted that Khasanovich ${ }^{64}$ (1959) pointed out that the material does not remain isotropic at large deformations, and hence the integrand in Equation 5 should be multiplied by a factor $\mu$ which takes into account the anisotropy of linear compressibility for a stretched material. If the elastomer obeys the kinetic theory stress-strain law derived by James and Guth ${ }^{46}$ (1947), then Khasanovich showed that:

$$
\mu=\frac{3}{\lambda^{2}+2}
$$

and consequently Equation 5 becomes: 


$$
\frac{\Delta V}{V_{0}}=\frac{E}{3 B}\left(1-\frac{1}{\lambda}\right)
$$

The comparison carried out by Fedors and Landel ${ }^{30}$ highlighted that at small elongations, i.e. less than 2 , the predictions of the various proposals correspond well to the experimental data. At large elongations, however, the predictions diverge. This is explained by the fact that Gee's expression is formulated for small elongations and that for large deformations, other phenomena such as crystallization and cavity nucleation and growth occur in the bulk material.

\section{B. MODELING THE REVERSIBLE CHANGE IN VOLUME UNDER MULTIAXIAL LOADING CONDITIONS}

To model the volume changes accompanying the deformation of rubber, the basis of isotropic elastic theory is applied. We start with the multiplicative decomposition of the deformation gradient $F=\operatorname{Grad} \vec{\phi}(\vec{X}, t)$ of a material point $\vec{X}$ at time $t$ into a volumechanging part and a volume-preserving part:

$$
F=\hat{F} \bar{F}
$$

$\vec{x}=\vec{\phi}(\vec{X}, t)$ denotes the deformation. The volume-preserving part is written:

$$
\bar{F}=J^{\frac{1}{3}} F, \operatorname{det} \bar{F}=1
$$

$J \equiv \operatorname{det} F$ and the volume-changing part $\widehat{F}=J^{\frac{1}{3}} I$ are used to define the unimodular left and right Cauchy-Green tensors, respectively:

$$
\bar{C}=\bar{F}^{T} \bar{F}, \bar{B}=\bar{F} \bar{F}^{T}
$$

$\operatorname{det} \bar{C}=\operatorname{det} \bar{B}=1$, which can be expressed relative to the original Cauchy-Green tensors $C=F^{T} F$ and $B=F F^{T}$ via: 


$$
\bar{C}=J^{-\frac{2}{3}} C \text { and } \bar{B}=J^{-\frac{2}{3}} B
$$

The three first invariants of each of the previous tensors are defined by:

$$
I_{C}=\operatorname{tr} C, I I_{C}=\frac{1}{2}\left((\operatorname{tr} C)^{2}-\operatorname{tr} C^{2}\right), I I I_{C}=\operatorname{det} C
$$

and

$$
I_{\bar{C}}=\operatorname{tr} \bar{C}, I I_{\bar{C}}=\frac{1}{2}\left((t r \bar{C})^{2}-\operatorname{tr} \bar{C}^{2}\right), I I I_{\bar{C}} \equiv J^{2}=1
$$

Based on the multiplicative decomposition defined in Equation 31, we assume a decoupled constitutive representation of the free energy function:

$$
W\left(J, I_{\bar{C}}, I I_{\bar{C}}\right)=U(J)+W\left(I_{\bar{C}}, I I_{\bar{C}}\right)
$$

so that the resulting stress state decomposes into a pure hydrostatic and a pure deviatoric part. The volumetric part of the strain energy function $U(J)$ is defined by $K \hat{U}(J)$ and corresponds to a penalty function. $\widehat{U}(J)$ denotes the principal function of the determinant $J$. One of the simplest expression commonly used for $\widehat{U}(J)$ is $\frac{1}{2}(J-1)^{2}$. In the literature, many other expressions of $\hat{U}(J)$ have been proposed. ${ }^{63,65-72}$ The form of $\hat{U}(J)$ is chosen with respect to the convexity requirement for the volumetric part of the strain-energy function that implies $U(J) \rightarrow \infty$ for $J \rightarrow 0$ and $J \rightarrow \infty$ as well as $U^{\prime \prime}(J) \geq 0$ so that a volumetric compression or stretch yields hydrostatic pressure or tension ${ }^{72}$.

Next, we present the prediction of relative volume variation expressed relative to the principal stretches instead of the invariants of the Cauchy-Green tensors (see Equation 37). For this purpose, the modified principal stretches $\bar{\lambda}_{i}$ are introduced in the form ${ }^{73}$ :

$$
\bar{\lambda}_{i}=\lambda_{i} J^{-\frac{1}{3}}
$$


This expression is similar to Equation 10 where $\bar{\lambda}_{i}$ corresponds to $\alpha_{i}$, the ratio between the final length of the network $l_{i}$ and its the initial undistorted length at volume $V$ with solvent $l_{S i}$ along the $i$ th coordinate direction. Thus:

$$
\bar{\lambda}_{1} \bar{\lambda}_{2} \bar{\lambda}_{3}=1
$$

Thus in turn, the strain energy density of an isotropic elastic solid can be considered as a function of $\bar{\lambda}_{1}, \bar{\lambda}_{2}, \bar{\lambda}_{3}$ and $J$, symmetrical in $\bar{\lambda}_{1}, \bar{\lambda}_{2}, \bar{\lambda}_{3}$. The principal Cauchy stresses $\sigma_{i}$ derive from the strain energy density according to:

$$
J \sigma_{i}=\lambda_{i} \frac{\partial W}{\partial \lambda_{i}}(i=1,2,3)
$$

and using the modified principal stretches, Equation 40 becomes:

$$
J \sigma_{i}=\sum_{j=1}^{3} \lambda_{i} \frac{\partial \bar{\lambda}_{j}}{\partial \lambda_{i}} \frac{\partial W}{\partial \bar{\lambda}_{j}}+J \frac{\partial W}{\partial J}
$$

which can be rewritten as follows:

$$
J \sigma_{i}=\frac{2}{3} \bar{\lambda}_{i} \frac{\partial W}{\partial \bar{\lambda}_{i}}-\frac{1}{3} \bar{\lambda}_{j} \frac{\partial W}{\partial \bar{\lambda}_{j}}-\frac{1}{3} \bar{\lambda}_{k} \frac{\partial W}{\partial \bar{\lambda}_{k}}+J \frac{\partial W}{\partial J}
$$

With respect to uniaxial tension and considering that the relative volume change $J-1$ is of the order of $0.01 \%, \operatorname{Ogden}^{73}$ (1976) introduced the variable $\varepsilon \equiv J-1$ and the notation $\widehat{W}(\bar{\lambda}, J) \equiv \hat{W}\left(\bar{\lambda}, \bar{\lambda}^{-\frac{1}{2}}, \bar{\lambda}^{-\frac{1}{2}}, J\right)$ and expanded $\widehat{W}(\bar{\lambda}, J)$ about $J=1$ to the second power in $\varepsilon$. Thus, one can write:

$$
\widehat{W}(\bar{\lambda}, J)=\widehat{W}(\bar{\lambda}, 1)+\varepsilon \frac{\partial \widehat{W}}{\partial J}(\bar{\lambda}, 1)+\frac{1}{2} \varepsilon^{2} \frac{\partial^{2} \widehat{W}}{\partial J^{2}}(\bar{\lambda}, 1)
$$

and the relative volume change $\varepsilon$ is given by: 


$$
\varepsilon=\left(\frac{1}{2} \bar{\lambda} \frac{\partial \widehat{W}}{\partial \lambda}(\bar{\lambda}, 1)-\frac{\partial \widehat{W}}{\partial \lambda}(\bar{\lambda}, 1)\right) / \frac{\partial^{2} \widehat{W}}{\partial J^{2}}(\bar{\lambda}, 1)
$$

Let us consider, for example, a certain class of strain energy densities introduced by $\operatorname{Ogden}^{63}(1972)$ :

$$
W=\frac{\mu_{n}}{\alpha_{n}}\left(\lambda_{1}^{\alpha_{n}}+\lambda_{2}^{\alpha_{n}}+\lambda_{3}^{\alpha_{n}}-3 J^{\frac{1}{3} \alpha_{n}}\right)+K g(J)
$$

where the $\mu_{n}$ s and $\alpha_{n}$ s are the material constants. The function $g(J)$ is such that $g(1)=g^{\prime}(1)=$ $0, g^{\prime \prime}(1)=1$. Moreover, $g^{\prime}(J)>0$ if $J>1$ and $g^{\prime}(J)<0$ if $J<1$. The prime denotes differentiation with respect to $J$. The principal Cauchy stresses associated with Equation 45 are:

$$
J \sigma_{i}=\mu_{n}\left(\bar{\lambda}_{i}^{\alpha_{n}}-1\right) J^{\frac{1}{3} \alpha_{n}}+K J g^{\prime}(J)
$$

The author showed that Equation 44 can be approximated by:

$$
\varepsilon=\frac{\mu_{n}}{K}\left(1-\bar{\lambda}^{-\frac{1}{2} \alpha_{n}}\right)+\mathrm{O}\left(\eta^{2}\right)
$$

where $\eta=\frac{\mu}{K}$. This expression corresponded to the work of Chadwick $^{74}$ (1974) and Flory $^{47}$ (1961), applied only to small stretches.

For higher stretches, the volume reaches a maximum, then falls to its initial value before decreasing steadily until rupture. To account for such a phenomenon, Ogden proposed to add a term, which involves a coupling between $J$ and the modified stretches, to the strainenergy function. Thus, for uniaxial tension, the relative volume change is given by:

$$
K \varepsilon=\mu_{n}\left(1-\bar{\lambda}^{-\frac{1}{2} \alpha_{n}}\right)-\bar{\chi}(\bar{\lambda})
$$

for equi-biaxial tension:

$$
K \varepsilon=\mu_{n}\left(1-\bar{\lambda}^{-2 \alpha_{n}}\right)-\bar{\chi}(\bar{\lambda})
$$


and for pure shear:

$$
K \varepsilon=\mu_{n}\left(1-\bar{\lambda}^{-\alpha_{n}}\right)-\hat{\chi}(\bar{\lambda})
$$

It should be noted that Sharda and Tschoegl ${ }^{75}$ (1976) used the same approach in which $\bar{\chi}(\bar{\lambda})$ also depends on $\mu_{n}$ and $\alpha_{n}$.

For uniaxial tension, Ogden proposed $\hat{\chi}(\bar{\lambda})$ in the form $\hat{\mu}\left(\bar{\lambda}^{\alpha}+2 \bar{\lambda}^{-\frac{1}{2} \alpha}-3\right)$ where $\hat{\mu}$ and $\alpha$ are real constants. This form allowed the author to fit the theory to the experimental data of Holt and McPherson ${ }^{11}$ and consequently to account phenomenologically for the influence of stress-induced crystallization on relative volume change.

To conclude on the modeling of the reversible change in volume of stretched rubber, numerous expressions of the relative volume have been proposed. All of them predicted volume change in the case of small deformations. However, for large deformations, the predictions diverge. This is due to the fact that large deformations generate heterogeneity in the bulk material, which is composed of numerous cavities which appear and grow. Finally, it should be noted that for large deformations in crystallizable rubbers, the approaches of $\operatorname{Ogden}^{73}$ and Sharda and Tschoegl ${ }^{75}$ account phenomenologically for the volume decrease due to the crystallization of the stretched polymer chains.

\section{NOTE ON MODELING THE IRREVERSIBLE CHANGE IN VOLUME UNDER MULTIAXIAL LOADING CONDITIONS}

Special experiments, as proposed by Gent and Lindley ${ }^{76}$ (1958), Gent and Wang ${ }^{77}$ (1991) and Legorju-Jago and Bathias ${ }^{78}$ (2002), were carried out to highlight the sudden initiation and growth of cavities in bulk material. For modeling, the cavitation phenomenon under hydrostatic loading conditions was studied considering the stability conditions for the 
sudden growth of microscopic cavities in the incompressible bulk (see for instance Ball $^{79}(1982)$ and Horgan and Abeyaratne $\left.{ }^{80}(1986)\right)$. This approach was then generalized to the other loading conditions by Hou and Abeyaratne ${ }^{81}$ (1992). To take into account the dependence of the stress-strain relationship on the growth of pre-existing cavities, the models incorporate damage variables into compressible hyperelastic approaches (see the review by Boyce and Arruda ${ }^{82}$ (2000)) to quantify the irreversible change in porosity. ${ }^{83-87}$ These models can also be extended to cavitation by adapting the rate equation for the damage variable ${ }^{88}$. Nevertheless, they are limited to small porosity values, so that the growing cavities do not intervene, and the irreversible change in volume seems to be associated with multiaxial loading conditions. In fact, under uniaxial loading conditions, the fact that cavities initiate and grow does not lead to a permanent set in terms of relative volume change.

\section{CONCLUSIONS AND PERSPECTIVES}

This paper has reviewed the literature on changes in the volume of rubber by gathering observations reported from the end of the $19^{\text {th }}$ until now. Usually, the volume variation is determined using dilatometry, but specific gravity, hydrostatic weighing or digital image correlation can also be used. The fact that the measurement technique differs from one author to another explains why the comparison of the results is difficult. Moreover, the strain rate, the time used for measurement, the accuracy, etc, are rarely given. Again, the material formulation is only precisely given in the recent studies. One can therefore imagine that there are as many results as there are compositions, and in some cases as there are measurement techniques. However, it seems reasonable to generalize the results obtained as follows:

(i) for non-crystallizable rubbers, the higher the elongation, the higher the relative volume variation. When the rubbers are filled, the concavity of the curve obtained in terms of 
relative volume change depends on the interaction between the fillers and the rubber matrix; (ii) crystallizable rubbers behave like non-crystallizable rubbers up to the elongation at the beginning of the crystallization. Above this elongation, the relative volume variation begins to decrease. When fillers are added, they act on the one hand as deformation concentrators and allow the crystallization to begin at a lower elongation, and on the other hand as amplifiers of the cavitation and cavity growth phenomenon. This explains why no decrease in the relative volume change is observed in filled crystallizable rubbers; only a decrease in the curve slope is apparent. To conclude, the vulcanization system can also act as fillers do. For instance, peroxide vulcanization, which links carbon atoms of macromolecules, concentrates the deformation more, i.e. allows crystallization to begin at a lower elongation, than sulfur vulcanization;

(iii) for both crystallizable and non-crystallizable filled rubbers under uniaxial cyclic loading, volume variation is a reversible process during the first cycles. No residual change in volume is observed after the first cycles. The maximum value of the relative volume change is obtained during the first cycle. Contrary to stress, volume variation is stabilized after the first cycle;

(iv) in crystallizable filled rubbers and contrary to non-crystallizable filled rubbers, a hysteresis loop is also observed in the volume variation curve for the second and the third cycles. This loop results from the difference between crystallization and crystallite melting kinetics.

Concerning the modeling of the change in volume, all of the approaches proposed predict volume change in the case of small deformations. For large deformations, however, the predictions diverge. This is mainly due to the fact that these approaches do not account for the change in the rubber microstructure. 
As a perspective, volume variation in rubber stretched under multiaxial loading conditions is a question of importance, and more particularly the fact that such loading conditions could generate an irreversible volume change. Until now, the effect of loading multiaxiality on volume variation has only been studied under the particular loading case of hydrostatic tension.

\section{REFERENCES}

${ }^{1}$ J. Gough, Proc. Lit. Phil. Soc. Manchester, 2nd, ser. 1, 288 (1805).

${ }^{2}$ J. P. Joule, Phil. Mag. 4th 14, 227 (1857).

${ }^{3}$ H. Bouasse and Z. Carrière, Ann. Fac. Sci. Toulouse 5, 257 (1903).

${ }^{4}$ W. L. Holt, Ind. Eng. Chem. 23, 1471 (1931).

${ }^{5}$ L. Mullins, RubBer CHEM. TeChnOL. 21, 281 (1948).

${ }^{6}$ Joule, J. P. "India-rubber in: The Scientific Papers of James Prescott Joule, volume 1.” Phys. Soc. (London), Taylor and Francis, 1884.

${ }^{7}$ A. Mallock, Proc. Roy. Soc. London 46, 233 (1889).

${ }^{8}$ W. Thomson (Lord Kelvin), (1890). Reported by H. F. Schippel In: Ind. Eng. Chem. 12, 33 (1920).

${ }^{9}$ H. F. Schippel, J. Ind. Eng. Chem. 12, 33 (1920).

${ }^{10}$ P. Hidnert, B. S. J. Research, 1, 771, R.P. 29 (1928).

${ }^{11}$ W. L. Holt and A. T. McPherson, J. res. Natl. Bur. Stand. 17, 657 (1936).

${ }^{12}$ G. Gee, J. Stern and L. R. G. Treloar, Trans. Faraday. Soc. 46, 1101 (1950).

${ }^{13}$ L. Mullins, and N. R. Tobin, RubBer ChEM. TEChNOL. 30, 551 (1957).

${ }^{14}$ P. Kumar, Y. Fukahori, A. G. Thomas and J. J. C. Busfield, J. Polym. Sci. Part B: Polym. Phys. 45, 3169 (2007). 
${ }^{15}$ J.-M. Chenal, C. Gauthier, L. Chazeau, L. Guy and Y. Bomal, Polymer 48, 6893 (2007).

${ }^{16}$ J.-B. Le Cam and E. Toussaint, Macromolecules 41, 7579 (2008).

${ }^{17}$ J.-B. Le Cam and E. Toussaint, Mech. Mater. 41, 898 (2009).

${ }^{18}$ H. Feuchter, Gummi-Ztg. 39, 1167 (1925).

${ }^{19}$ M. F. Acken, W. E. Singer, and W. P.Davey, Ind. Eng. Chem. 24, 54 (1932).

${ }^{20}$ J. D. Long, W. E. Singer and W. P. Davey, Ind. Eng. Chem. 26, 543 (1934).

${ }^{21}$ P. A. Thiessen and W. Wittstadt, RubBer CHEM. TeChNOL. 9, 52 (1936).

${ }^{22}$ Bureau of Standards, Bur. Standards Tech. News Bull. 201, 6 (1934).

${ }^{23}$ W. E. Thibodeau and A. T. McPherson, J. Research NBS, RP 753, 13, 887 (1934).

${ }^{24}$ L. A. Wood and F. L. Roth, J. Appl. Phys. 15, 781 (1944).

${ }^{25}$ G. Gee, Trans. Faraday. Soc. 42, 585 (1946).

${ }^{26}$ F. G. Hewitt and R. L. Anthony, RubBer Chem. TeChnOL. 32, 428 (1959).

${ }^{27}$ R. Christensen and C. Hoeve, RubBer CheM. TeChnOL. 43, 1473 (1970).

${ }^{28}$ R. W. Penn, Trans. Soc. Rheol. 14, 509 (1970).

${ }^{29}$ J. Goebel and A. Tobolsky, Macromolecules, 44, 208 (1971).

${ }^{30}$ R. F. Fedors and R. F. Landel, RubBER CHEM. TECHNOL. 43, 887 (1970).

${ }^{31}$ R. Shuttleworth, RUBber CHEM. TECHNOL. 42, (1969).

${ }^{32}$ W. F. Reichert, M. K. Hopfenmüller and D. Göritz, J. Mater. Sci. 22, 3470 (1987).

${ }^{33}$ T. Shinomura and M. Takahashi, RubBer ChEM. TeChnOL. 43, 1015; 43, 1025 (1970).

${ }^{34}$ D. Y. Wu, S. Bateman and M. Partlett, Compos. Sci. Technol. 67, 1909 (2007).

${ }^{35}$ W. Dierkes, J. Elastomers Plast. 28, 257 (1996).

${ }^{36}$ M. J. Myhre and D. A. Mackillop, Rubber World 214, 42 (1996).

${ }^{37}$ J. Ramier, L. Chazeau, C. Gauthier, L. Stelandre, L. Guy and E. Peuvrel-Disdier, J. Mater. Sci. 42, 8130 (2007).

${ }^{38}$ S. Trabelsi, P.-A. Albouy and J. Rault, Macromolecules 35, 10054 (2002). 
${ }^{39}$ A. E. H. Love, Courier Dover Publications, (First Edition: 1892), 1944.

${ }^{40}$ J. Pellicer, J. A. Manzanares, J. Zúniga, P. Utrillas and J. Fernandez, J. Chem. Education 78, 263 (2001).

${ }^{41}$ M. Shen, W. F. Hall and R. E. Dewames, Polym. Rev. 2, 183 (1968).

42،"Rubberlike Elasticity - A Molecular Primer,”, J. E. Mark and B. Erman, J. Wiley and Sons Eds, New-York, 1988.

${ }^{43}$ P. J. Flory and J. Rehner, J. Chem. Phys. 11, 512 (1943).

${ }^{44}$ L. R. G. Treloar, “The Physics of Rubber Elasticity” $3{ }^{\text {rd }}$ Ed., Clarendon Press, Oxford, 1975.

${ }^{45}$ P. J. Flory, "Principles of Polymer Chemistry," Cornell University Press, New York, 1953.

${ }^{46}$ H. M. James and E. Guth, J. Chem. Phys. 15, 669 (1947).

${ }^{47}$ P. J. Flory, Trans. Faraday Soc. 57, 829 (1961).

${ }^{48}$ T. L. Smith, Trans. Soc. Rheol. 6, 61 (1962).

${ }^{49}$ G. M. Bartenev, Kolloid Zh. 11, 2 (1949).

${ }^{50}$ K. C. Valanis and R. F. Landel, J. Appl. Phys. 38, 2997 (1967).

${ }^{51}$ G. M. Martin, F. L. Roth and R. D. Stiehler, Trans. Inst. Rubber Ind. 32, 189 (1956).

${ }^{52}$ M. Mooney, J. Appl. Phys. 11, 582 (1940).

${ }^{53}$ L. R. G. Treloar, Trans. Faraday Soc. 39, 36; 39, 241 (1943).

${ }^{54}$ R. S. Rivlin, Phil. Trans. R. Soc. A240, 459 (1948).

${ }^{55}$ R. S. Rivlin, Phil. Trans. Roy. Soc. A241, 379 (1948).

${ }^{56}$ V. L. Biderman, Rascheti na Prochnost, 40 (1958).

${ }^{57}$ L. J. Hart-Smith, Z. angew. Math. Phys. 17, 608 (1966).

${ }^{58}$ O. H. Yeoh, RUBber CHEM. TECHNOL. 66, 754 (1993).

${ }^{59}$ O. H. Yeoh and P. D. Fleming, J. Polym. Sci. . Part B: Polym. Phys. 35, 1919 (1997).

${ }^{60}$ A. N. Gent, Rubber. Chem. TeChnOl. 69, 59 (1996).

${ }^{61}$ D. W. Haines and W. D. Wilson, J. Mech. Phys. Solids 27, 345 (1979). 
${ }^{62}$ A. N. Gent and A. G. Thomas, J. Polym. Sci. 28, 625 (1958).

${ }^{63}$ R. W. Ogden, Proc. R. Soc. London 326, 565 (1972).

${ }^{64}$ T. N. Khasanovich, J. Appl. Phys. 30, 948 (1959).

${ }^{65}$ J. C. Simo and R. L. Taylor, Comp. Meth. Appl. Mech. Engrg. 35, 107 (1982).

${ }^{66}$ J. C. Simo, R. L. Taylor and K. S. Pister, Comp. Meth. Appl. Mech. Engrg. 51, 177 (1985).

${ }^{67}$ J. C. Simo and R. L. Taylor, Comp. Meth. Appl. Mech. Engrg. 85, 273 (1991).

${ }^{68}$ C. Miehe, Int. J. Num. Meth. Eng. 37, 1981 (1994).

${ }^{69}$ C. H. Liu, G. Hofstetter and H. A. Mang, Eng. Computation 11, 111 (1994).

${ }^{70}$ F. D. Murnaghan, "Finite deformation of an elastic Solid". Chapmann and Hall Eds, NewYork, 1951.

${ }^{71}$ S. Hartmann, Comp. Meth. Appl. Mech. Engrg. 191, 1439 (2002).

${ }^{72}$ S. Hartmann and P. Neff, Int. J. Solids Struct. 40, 2767 (2003).

${ }^{73}$ R. W.Ogden, J. Mech. Phys. Solids 24, 323 (1976).

${ }^{74}$ P. Chadwick, Phil. Trans. Roy. Soc. London A276, 371 (1974).

${ }^{75}$ S. C. Sharda and N. W. Tschoegl, Trans. Soc. Rheol. 20, 361 (1976).

${ }^{76}$ A. N. Gent and P. Lindley Proc. Roy. Soc. 249, 195 (1958).

${ }^{77}$ A. N. Gent and C. Wang, J. mater. sci. 26, 3392 (1991).

${ }^{78}$ K. Legorju-Jago and C. Bathias, Int. J. Fatigue 24, 85 (2002).

${ }^{79}$ J. M. Ball, Phil. Trans. Roy. Soc. London A306, 557 (1982).

${ }^{80}$ C. O. Horgan and R. Abeyaratne, J. Elast. 16, 189 (1986).

${ }^{81}$ H.-S. Hou and R. Abeyaratne, J. Mech. Phys. Solids 40, 571 (1992).

${ }^{82}$ M. C. Boyce and E. M. Arruda, Rubber CheM. TeChnOL. 73, 505 (2000).

${ }^{83}$ F. Andrieux, K. Saanouni, and F. Sidoroff, C. R. Mec. Sciences II-B 324, 281 (1997).

${ }^{84}$ A. Dorfmann, K. N. G. Fuller and R. W. Ogden, Int. J.Solids Struct. 39, 1845 (2002). 
${ }^{85}$ K. Layouni, L. Laiarinandrasana and R. Piques, “Constitutive Models for Rubber III,” J. J. C. Busfield and A. H. Muhr Eds, page 292. Balkema, 2003.

${ }^{86}$ J. Li, D. Mayau and V. Lagarrigue, J. Mech. Phys. Solids 56, 953 (1997).

${ }^{87}$ E. Verron, G. Chagnon and J.-B. Le Cam, "Constitutive Models for Rubber VI," G. Heinrich, M. Kaliske, A. Lion and S. Reese Eds, page 279. Balkema, 2009.

${ }^{88}$ A. Dorfmann, K. N. G. Fuller and R. W. Ogden, “Constitutive Models for Rubber III,” J. J. C. Busfield and A. H. Muhr Eds, page 253. Balkema, 2003. 


\section{LISTE OF FIGURES}

FIG. 1. - Change in volume of stretched rubbers at different elongations and with different quantities of pigment (see Figures 1 to 7 in reference 9).

Fig. 2. - Change in volume of rubber on stretching to different elongations at $25^{\circ} \mathrm{C}$ (see Figure 6 in reference 11$)$.

Fig. 3. - Change in volume of rubber when stretched and when released in a stepwise manner at $25^{\circ} \mathrm{C}$ (see Figure 7 in reference 11 ).

FIG. 4. - Modeling of the volume variation in carbon black-filled butyl and styrene butadiene rubber (see Figure 6 in reference 33).

FIG. 5. - A new mechanical quantity to analyze volume variation (see Figure 6 in reference $33)$.

FIG. 6. - Difference in the concavity of volume variation curves obtained for covering and coupling agents (see Figures 5(a) and 5(a) in reference 37).

FIG. 7. - Relative volume variation in filled and unfilled natural rubber versus elongation (see Figure 1(b) in reference 15).

FIG. 8. - Schematic illustration of the competition between decohesion/cavitation and crystallization in terms of relative volume variation (see Figure 2 in reference 15).

FIG. 9. - Relative volume variation over the first mechanical cycle in natural rubber (NR).

FIG. 10. - Relative volume variation over the first mechanical cycle in NR. The maximum elongation value is lower than that at the beginning of crystallization.

FIG. 11. - Relative volume variation over the first mechanical cycle in F-NR.

FIG. 12. - Relative volume variation over the third mechanical cycle in F-NR.

FIG. 13. - Relative volume variation over the third mechanical cycle in F-SBR. 


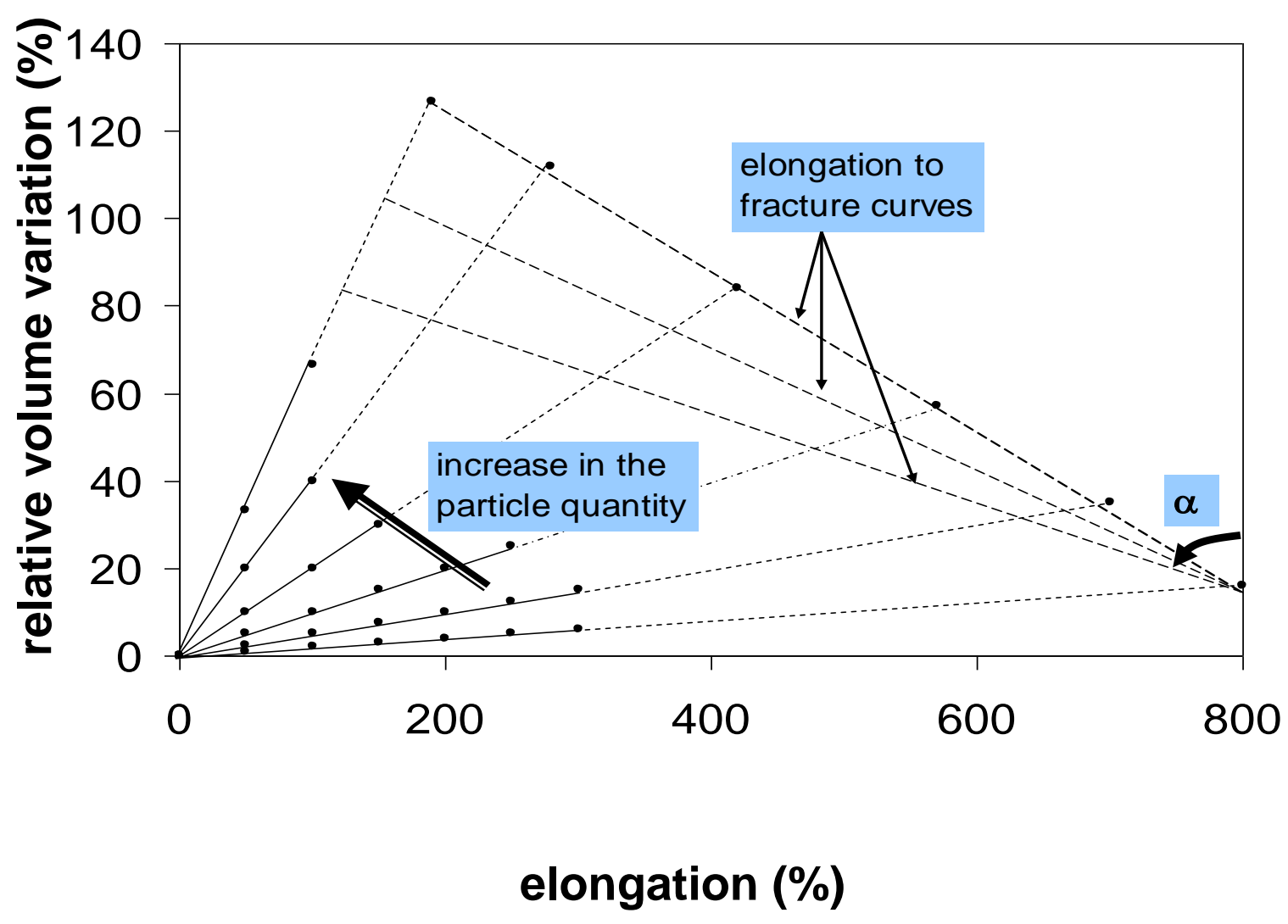

FIG. 1. - Change in volume of stretched rubbers at different elongations and with different quantities of pigment (see Figures 1 to 7 in reference 9). 


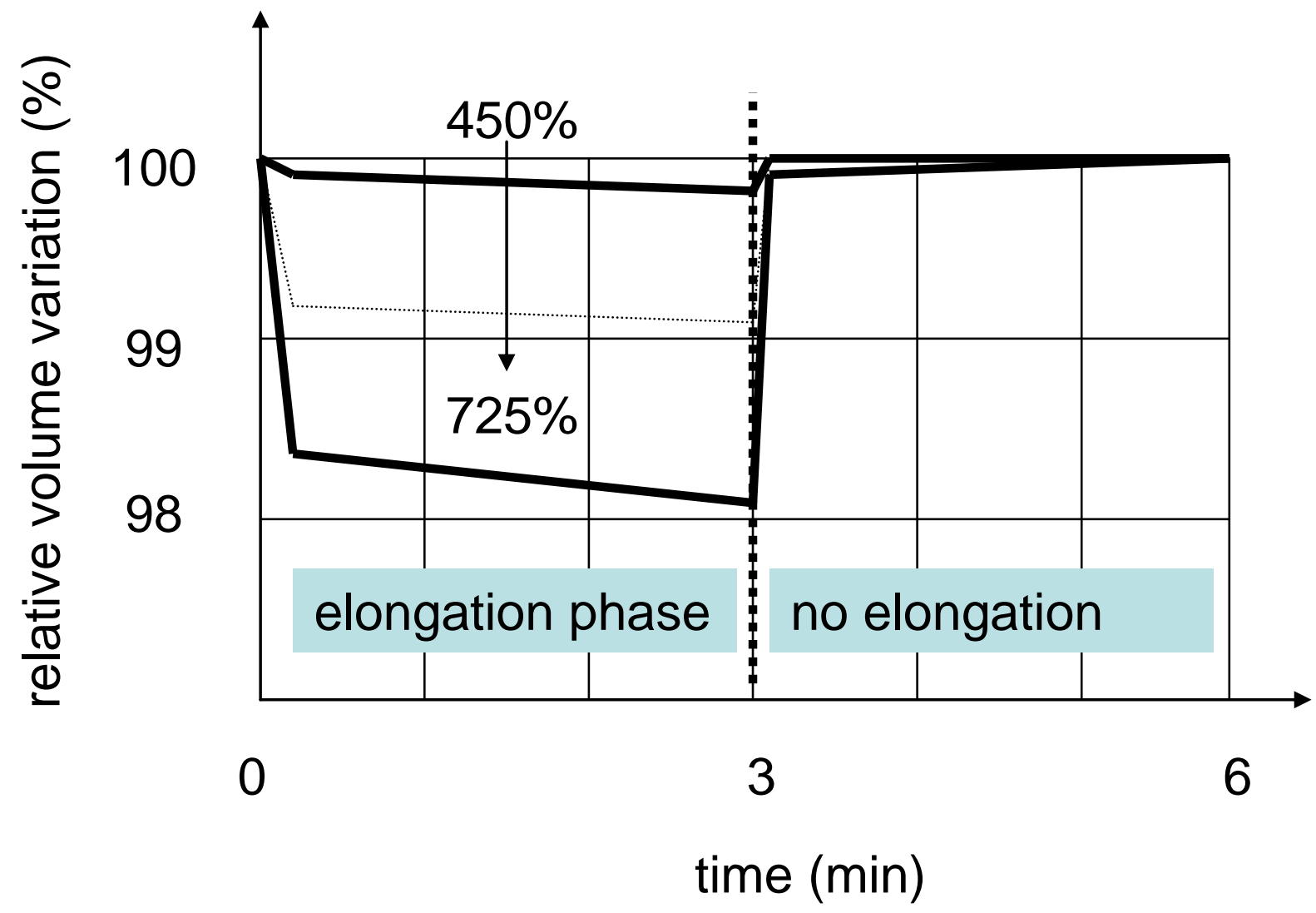

Fig. 2. - Change in volume of rubber on stretching to different elongations at $25^{\circ} \mathrm{C}$ (see Figure 6 in reference 11). 


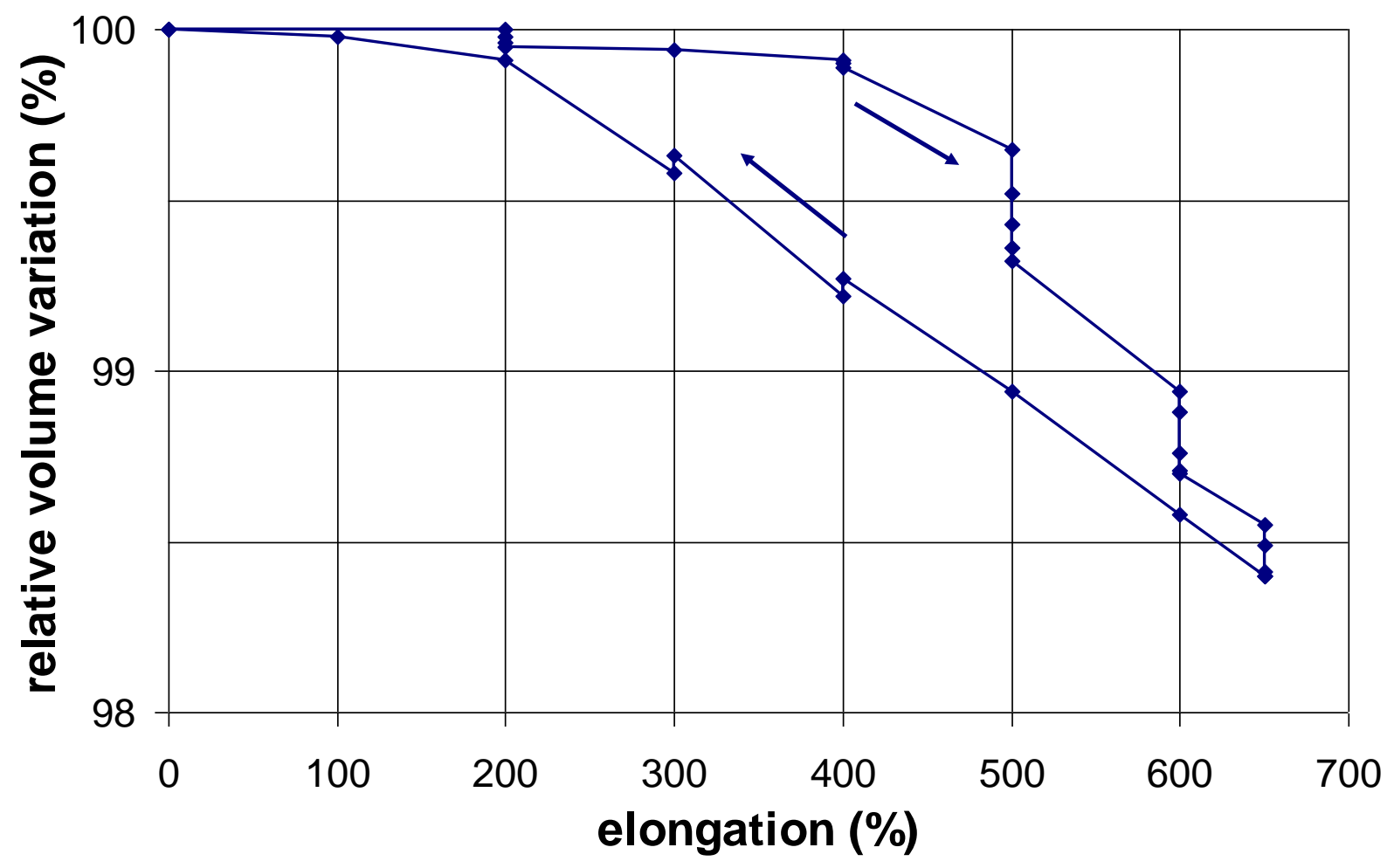

Fig. 3. - Change in volume of rubber when stretched and when released in a stepwise manner at $25^{\circ} \mathrm{C}$ (see Figure 7 in reference 11 ). 


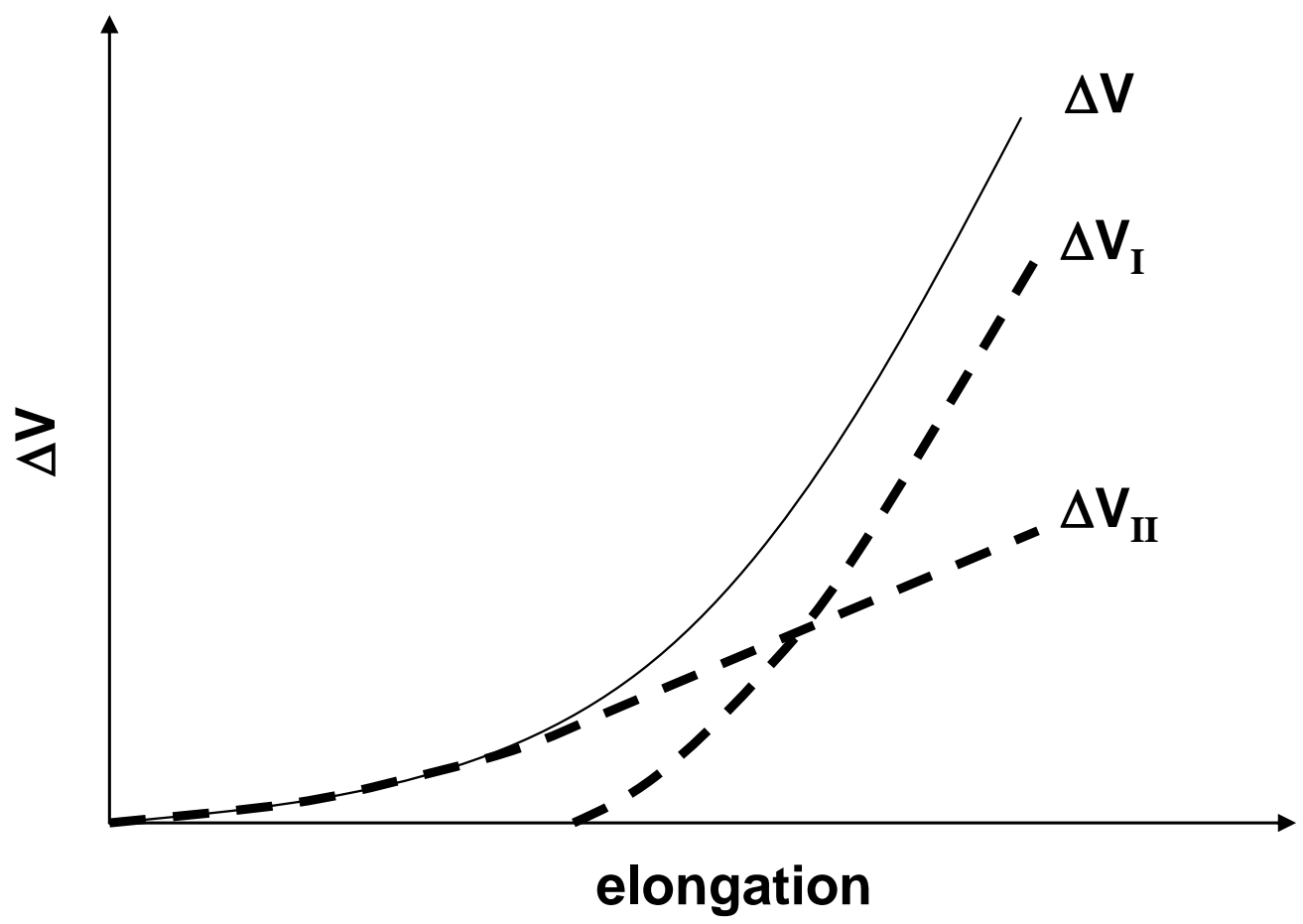

FIG. 4. - Modeling of the volume variation in carbon black-filled butyl and styrene butadiene rubber (see Figure 6 in reference 33). 


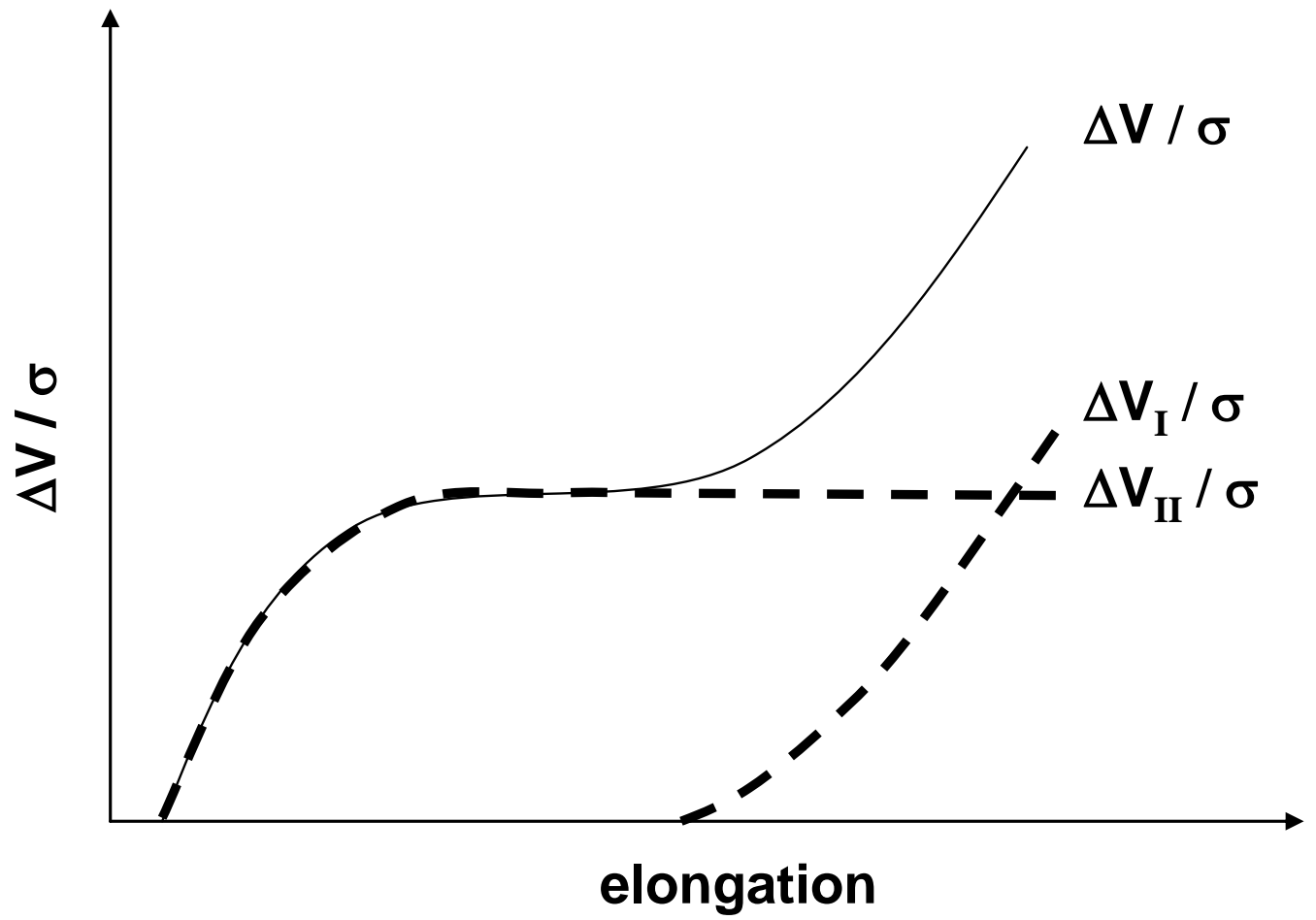

FIG. 5. - A new mechanical quantity to analyze volume variation (see Figure 6 in reference 33). 


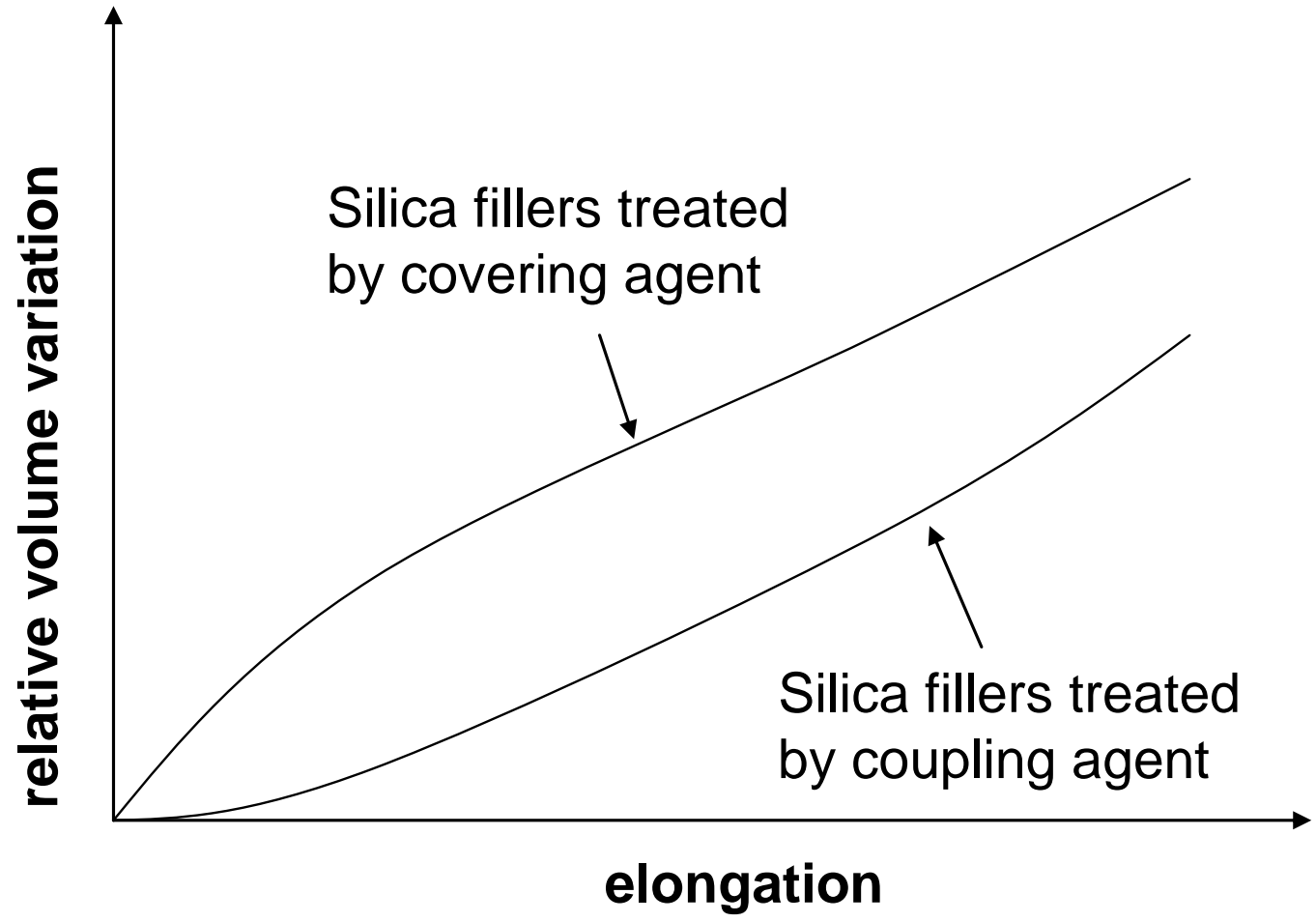

FIG. 6. - Difference in the concavity of volume variation curves obtained for covering and coupling agents (see Figures 5(a) and 5(a) in reference 37). 


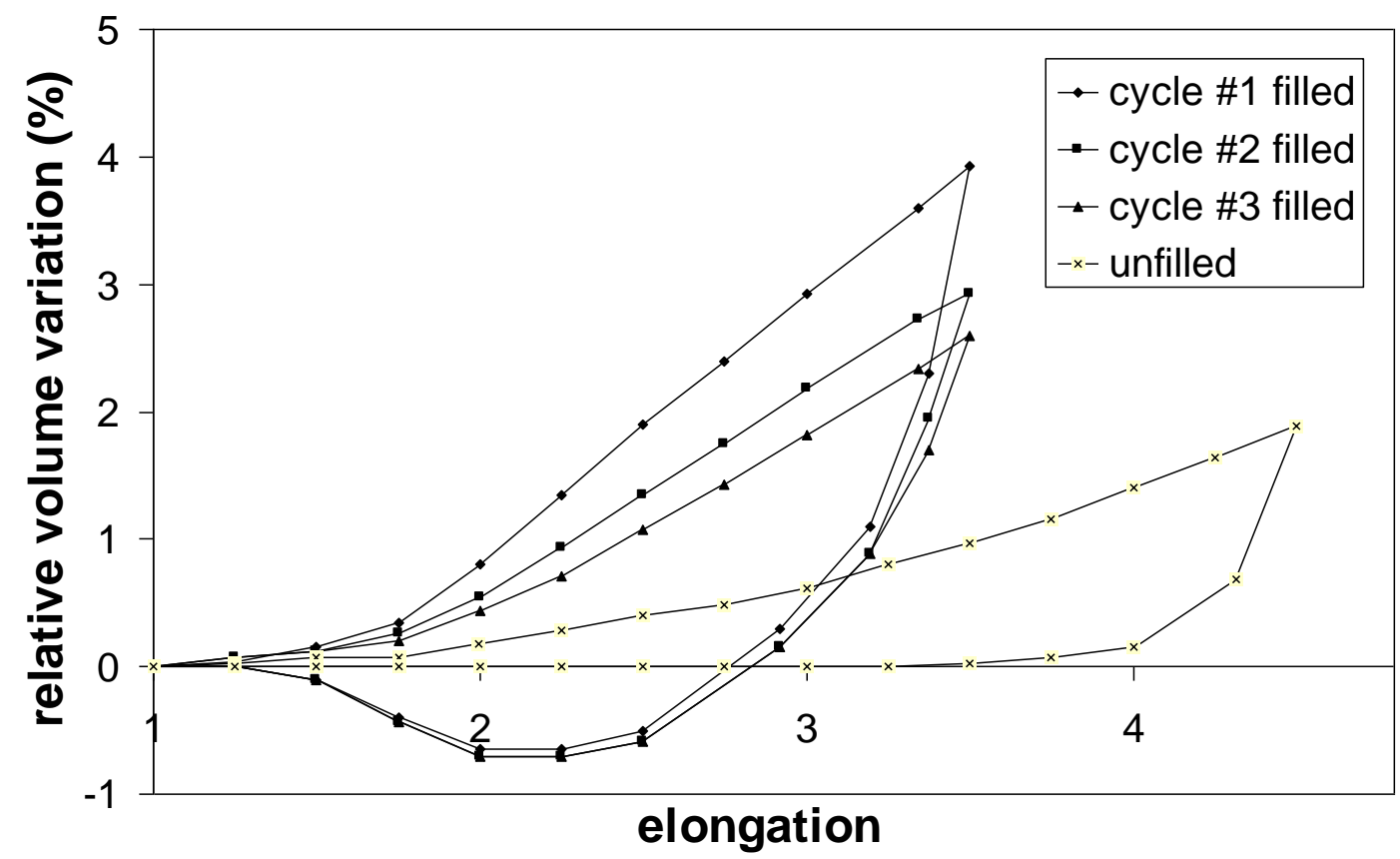

FIG. 7. - Relative volume variation in filled and unfilled natural rubber versus elongation (see Figure 1(b) in reference 15). 


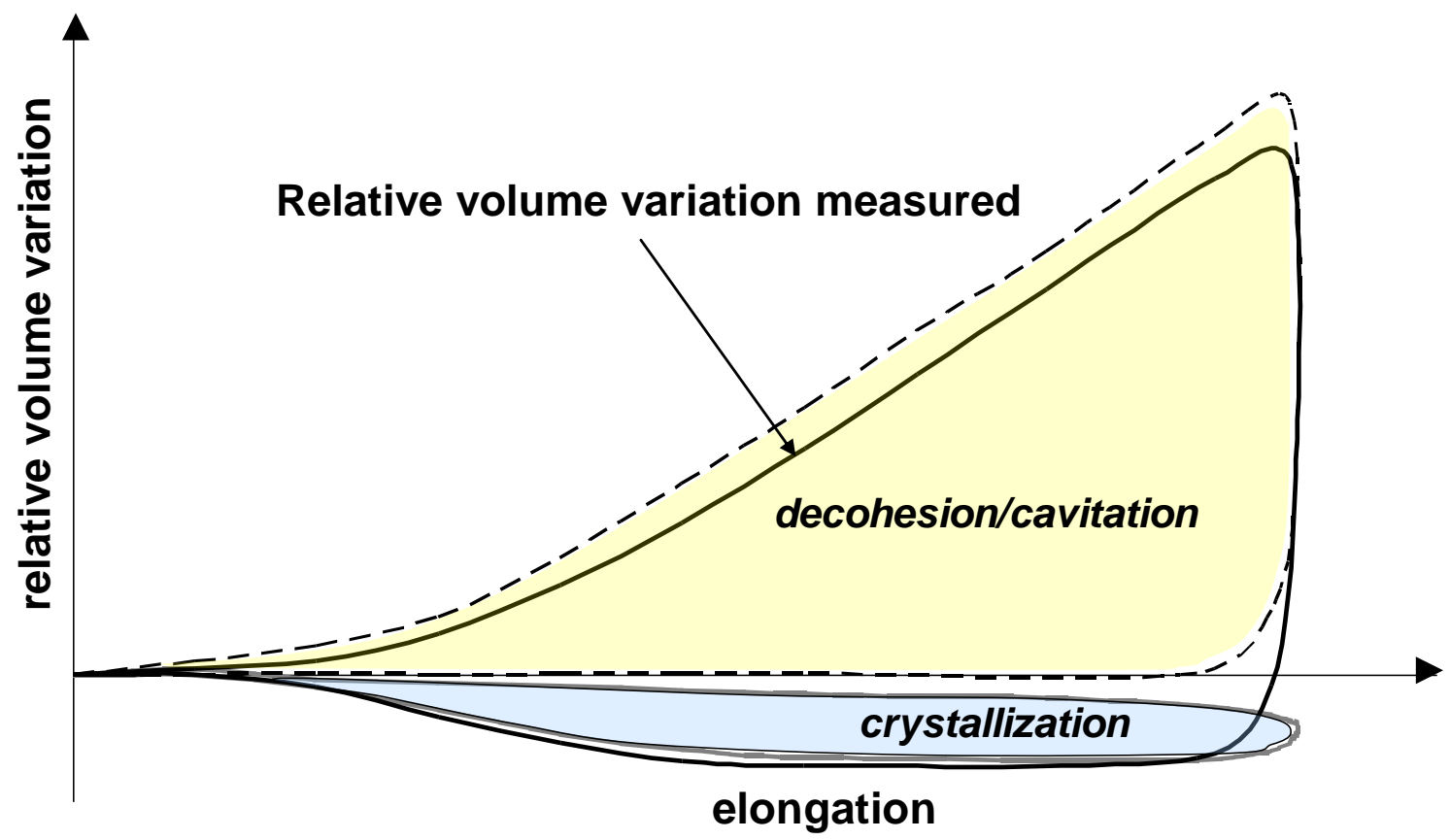

FIG. 8. - Schematic illustration of the competition between decohesion/cavitation and crystallization in terms of relative volume variation (see Figure 2 in reference 15). 


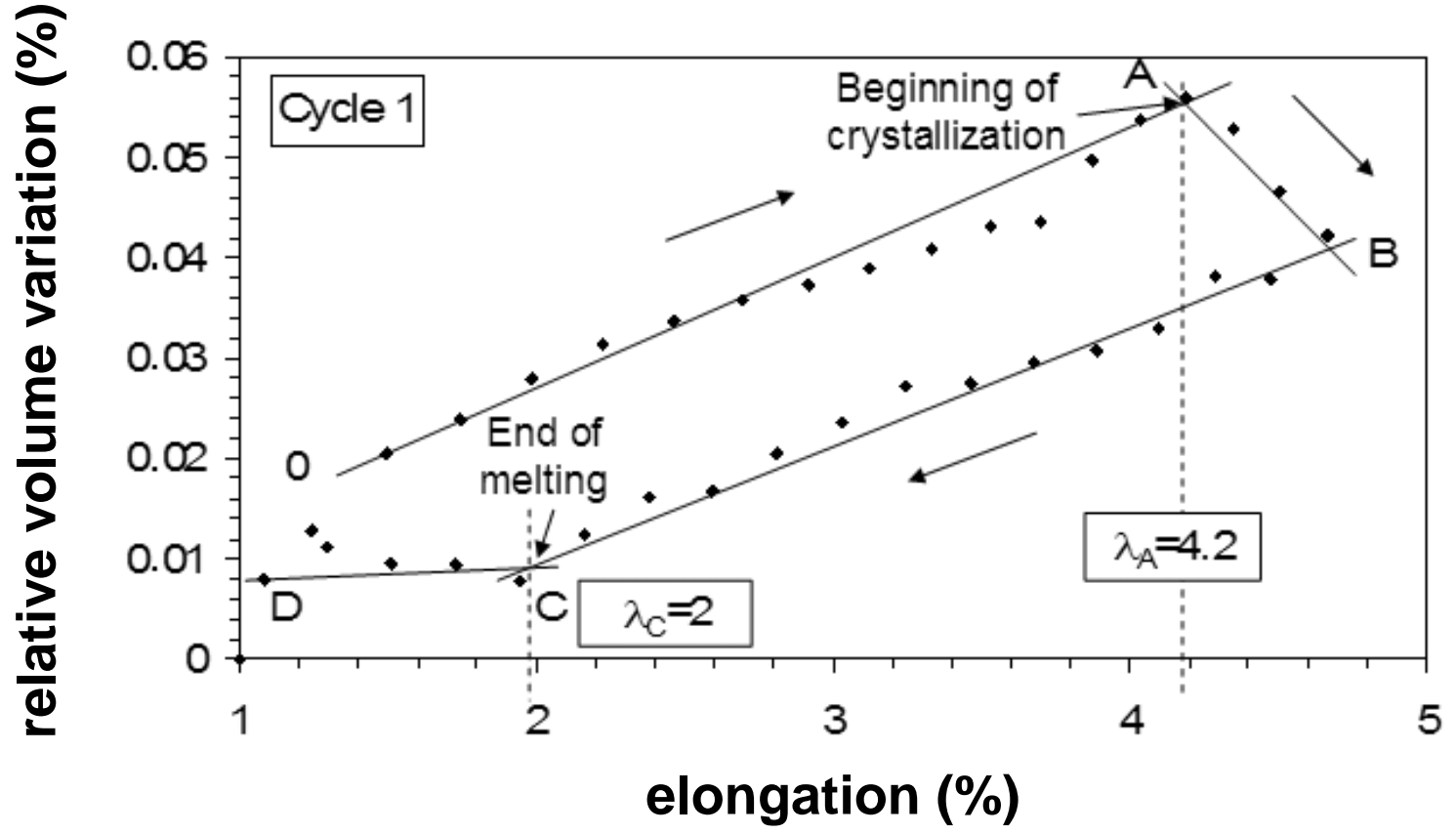

FIG. 9. - Relative volume variation over the first mechanical cycle in natural rubber (NR). 


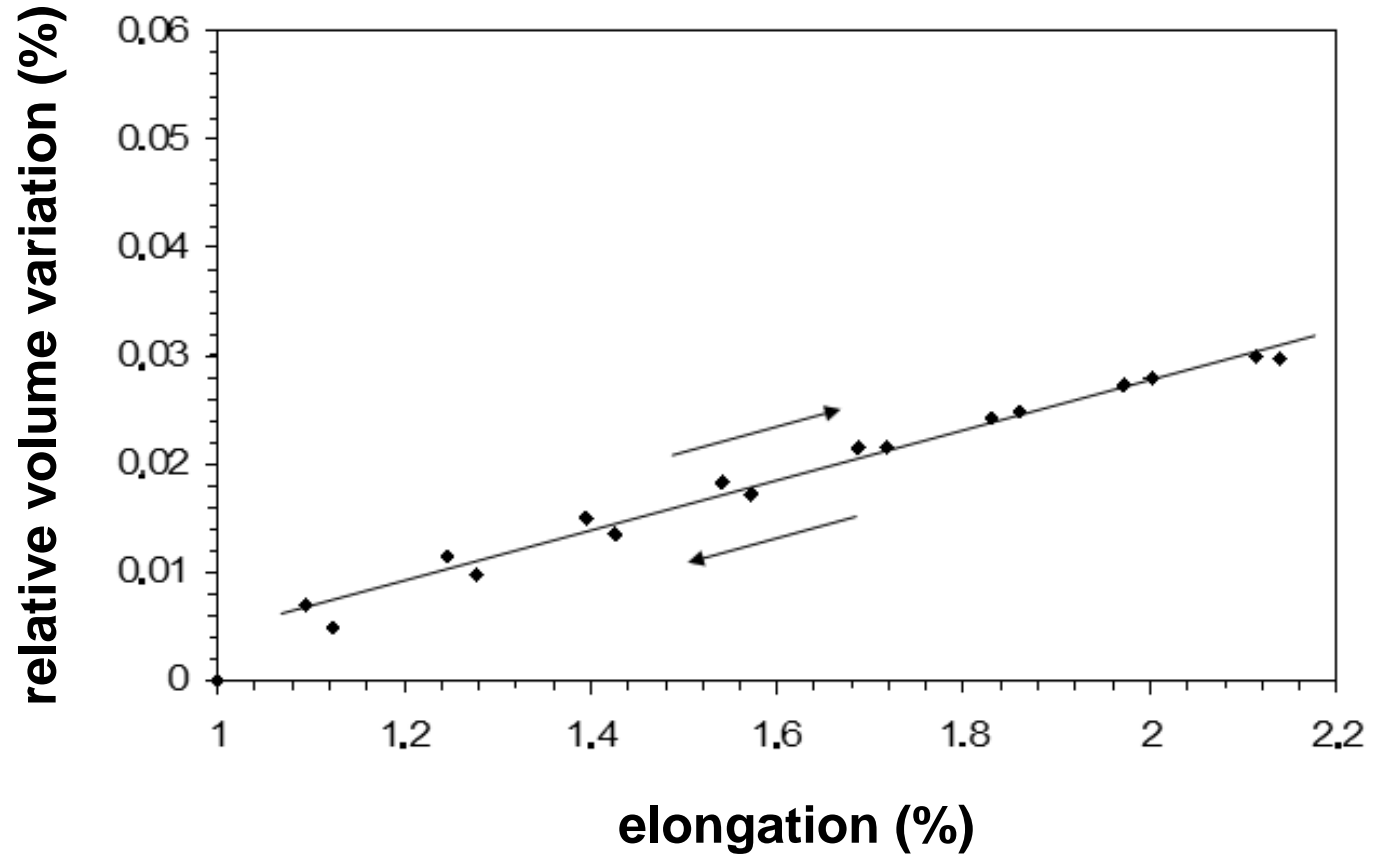

FIG. 10. - Relative volume variation over the first mechanical cycle in NR. The maximum elongation value is lower than that at the beginning of crystallization. 


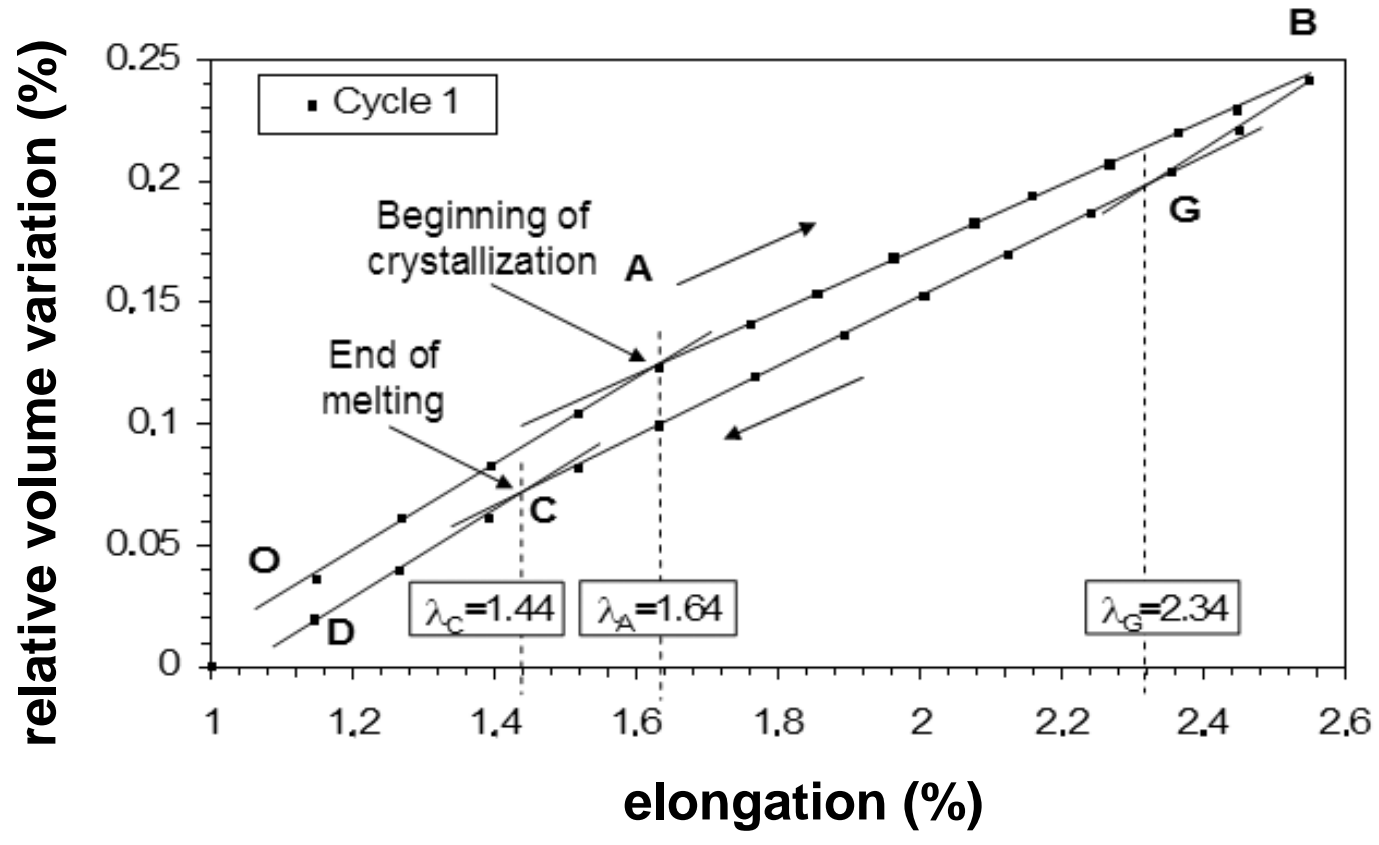

FIG. 11. - Relative volume variation over the first mechanical cycle in F-NR. 


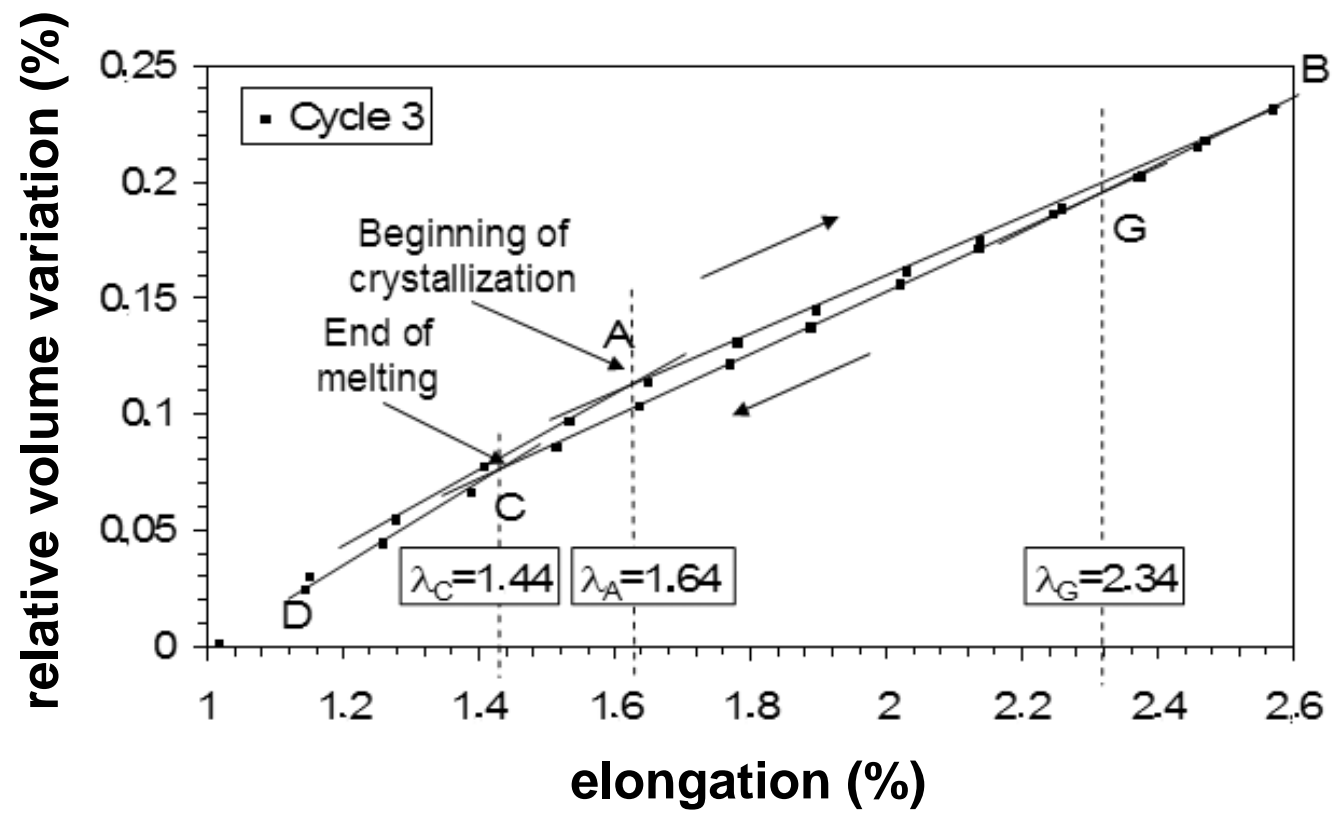

FIG. 12. - Relative volume variation over the third mechanical cycle in F-NR. 


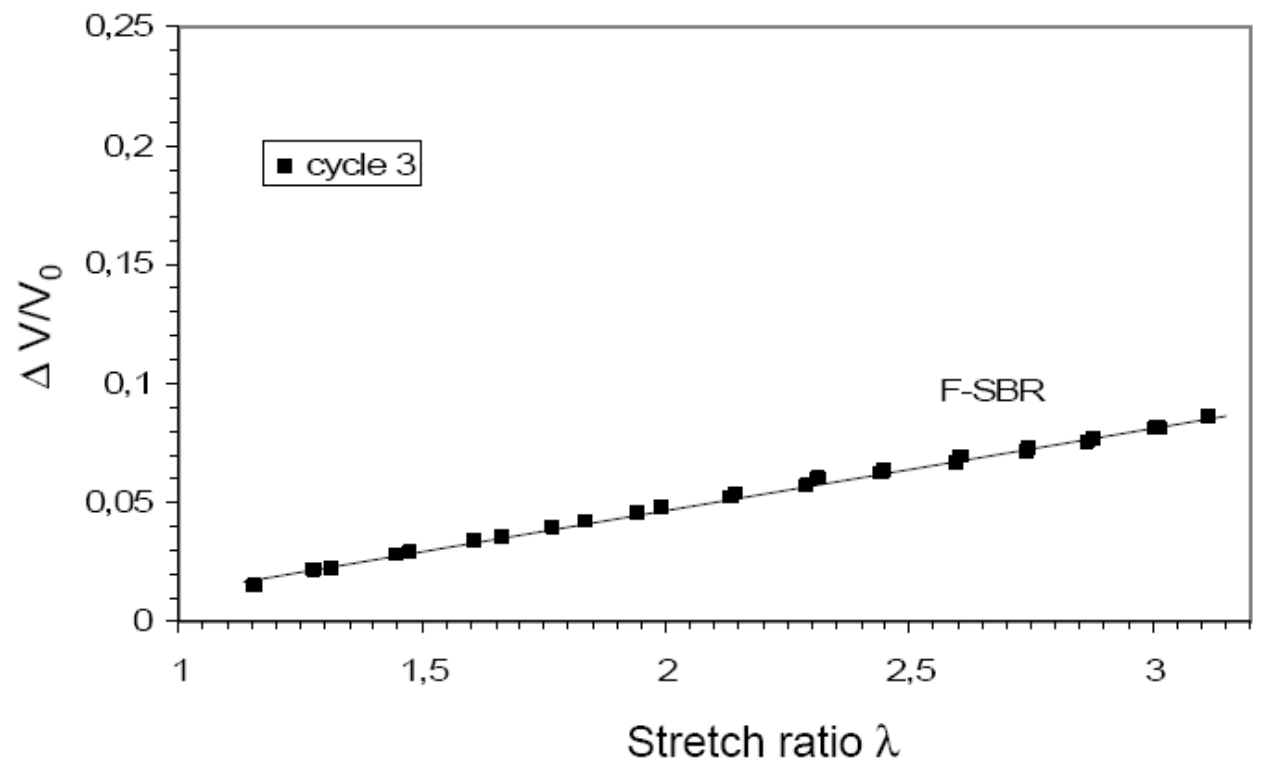

FIG. 13. - Relative volume variation over the third mechanical cycle in F-SBR. 